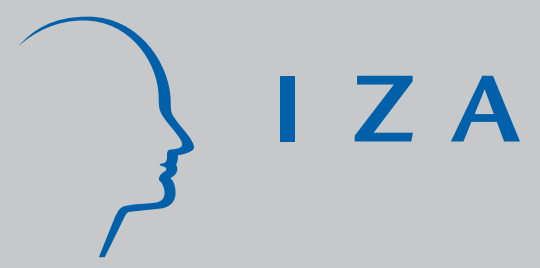

IZA DP No. 350

Unemployment Duration:

Competing and Defective Risks

J ohn T. Addison

Pedro Portugal

August 2001 


\title{
Unemployment Duration: Competing and Defective Risks
}

\author{
John T. Addison \\ Moore School of Business, University of South Carolina and IZA, Bonn \\ Pedro Portugal \\ Banco de Portugal and Universidade Nova de Lisboa
}

\author{
Discussion Paper No. 350 \\ August 2001
}

\author{
IZA \\ P.O. Box 7240 \\ D-53072 Bonn \\ Germany \\ Tel.: +49-228-3894-0 \\ Fax: +49-228-3894-210 \\ Email: iza@iza.org
}

This Discussion Paper is issued within the framework of IZA's research area Mobility and Fexibility of Labor Markets. Any opinions expressed here are those of the author(s) and not those of the institute. Research disseminated by IZA may include views on policy, but the institute itself takes no institutional policy positions.

The Institute for the Study of Labor (IZA) in Bonn is a local and virtual international research center and a place of communication between science, politics and business. IZA is an independent, nonprofit limited liability company (Gesellschaft mit beschränkter Haftung) supported by the Deutsche Post AG. The center is associated with the University of Bonn and offers a stimulating research environment through its research networks, research support, and visitors and doctoral programs. IZA engages in (i) original and internationally competitive research in all fields of labor economics, (ii) development of policy concepts, and (iii) dissemination of research results and concepts to the interested public. The current research program deals with (1) mobility and flexibility of labor markets, (2) internationalization of labor markets and European integration, (3) the welfare state and labor markets, (4) labor markets in transition, (5) the future of work, (6) project evaluation and (7) general labor economics.

IZA Discussion Papers often represent preliminary work and are circulated to encourage discussion. Citation of such a paper should account for its provisional character. 
IZA Discussion Paper No. 350

August 2001

\section{ABSTRACT}

\section{Unemployment Duration: Competing and Defective Risks}

This paper examines the determinants of unemployment duration in a competing risks framework with two destination states, namely, inactivity and employment. The major innovation is our recognition of defective risks. We first use a polynomial hazard function to test for the presence of two-sources of defective risks: search involving a random process of unlucky draws that yields a non-proper duration distribution; and a split-population model in which the decision by some individuals not to consider certain destination states produces a defective distribution. Having established the primacy of the latter model, we refine it using a more flexible piecewise-constant baseline hazard function. This specification broadly confirms our earlier findings but offers a more convincing explanation for positive and zero transition rates out of unemployment. Although we do not reject the null of proportionality, abandoning the proportionality assumption does not materially alter our conclusions.

JEL Classification: $\quad$ C41, J64, J65

Keywords: unemployment duration, competing risks, defective risks, non-proper distribution, split-population model

John T. Addison

Department of Economics

University of South Carolina

Columbia, SC 29208

U.S.A.

Tel.+ (001) 803-777-4608

Email: ecceaddi@darla.badm.sc.ed 


\section{Introduction}

This paper considers a model of unemployment duration in which exit from unemployment can result from finding a job or becoming inactive, two destinations that have been shown to be behaviorally distinct states (Flinn and Heckman, 1983). Use of a competing risks framework, while not yet commonplace in the duration literature, is becoming more familiar (see, for example, Han and Hausman, 1990; Meyer, 1990; Fallick, 1991; Narendranathan and Stewart, 1993). What is altogether less familiar is the notion exploited here that risks may be 'defective,' in the sense that certain destination states may not be considered by unemployed individuals, whose observed and unobserved characteristics may anyway rule them out as candidates for employment. The notion that unemployed individuals may be permanently trapped in joblessness is explored theoretically in Blanchard and Diamond (1994), Ljungqvist and Sargent (1998), and Ridder and van den Berg (2001).

We would argue that the idea that risks are defective is likely to be especially relevant to high unemployment/long jobless duration European labor markets in general and to their more sclerotic component markets such as Portugal - the subject of this empirical inquiry - in particular where unemployment may come to represent a near pathological end state. ${ }^{1}$ (In other nations, where unemployment may be less entrenched, the notion of defective risks might still usefully be deployed to analyze transitions into certain types of employment, such as open-ended employment versus fixed-term contracts or full-time versus part-time work) If certain destination states are not viable, the standard problems associated with aggregating over a number of exit modes will only be compounded. Specifically, as we shall show, there will be a bias in favor of negative duration dependence and one will tend to underpredict the probability of not changing state.

In this paper, we will consider two distinct statistical duration models that lend themselves to infinite durations, and thus to a defective risk. Our favored model is a socalled 'split-population model' in which some individuals do not contemplate (or are excluded from) certain labor markets options and thereby come to constitute different populations from those that do. In this case, the probability of moving from one state to another is zero from the outset. In particular, we will allow the proportion of stayers to be 
influenced by observed heterogeneity. This type of model, which generalizes the more conventional mover-stayer model allowing for regressors to influence the probability of being a stayer, was first applied by Schmidt and Witte (1989) to the recidivism phenomenon in criminal behavior. To our knowledge the only labor applications are by Yamaguchi (1992), Pudney and Thomas (1995), and Melkersson (1999), each of which has a narrower focus than the present paper. ${ }^{2}$ Yamaguchi considers the implications of permanent employment in Japan for labor market transitions. Pudney and Thomas investigate movements from unemployment to specific industry sectors. Melkersson studies the return to employment of a sample of Swedish disabled workers, distinguishing between three competing exits from unemployment: regular employment, sheltered employment, and inactivity.

But before considering the basics of our split-population model, however, it is important to point out that the presence of defective risks is quite compatible with other statistical duration models. In the second type of model considered here, we simply recognize that some specifications of the latent hazard (section III below) can deliver defective latent distributions - see, for example, Flinn and Heckman's (1982) use of a polynomial hazard function in a competing risks framework. Estimation of this type of model does not present major difficulties. In other words, there is nothing anomalous about defective distributions and they may emerge naturally in optimizing models (Heckman and Singer, 1985). As a case in point, Jovanovic (1979) derives an infinite horizon worker-firm matching model with a defective (inverse-Gaussian) job tenure distribution.

(Figure 1 near here)

The point is made in Figure 1. Panel (a) of the figure presents the density function from a (cubic) polynomial hazard function in time. The area under the function is shown to be less than 1; implicitly, the last term in the polynomial is negative. As a result, the hazard function crosses the time axis in panel (b) and, equivalently, at that same duration interval the survival function in panel (c) does not converge to zero but instead assumes and maintains indefinitely thereafter some constant positive value (i.e. the integrated hazard is not divergent). This possibility might well characterize a situation in which, as a result of chance, some portion of individuals searching for work are unlucky in their 
draws, that is, they fail to draw from the finite segment of the duration distribution. Expressed another way, each individual has a non-zero probability of ending up in a (latent) spell which lasts forever. The relevance of this possibility is clearly an empirical issue. We will tentatively label this model as a 'non-proper distribution model.'

Non-proper (or defective) distributions are not the sole source of infinite durations because there are other approaches admitting of defective risks. For example, consider the determinants of the age at which women give birth to their first child. The problem is that one may be sampling from two distinct subpopulations, one of which is made-up of infertile couples who will have 'infinite durations.' This very scenario is analyzed formally by Heckman and Walker (1990). The generalization of this mover-stayer model to more than one exit state is fairly simple. We argue that some unemployed individuals will consciously rule out the option of labor market withdrawal. At the same time, there will also be unemployed workers who, by virtue of their past choices or current skill endowments, will be unable to secure employment. Such individuals can be termed unemployables.

(Figure 2 near here)

The basic elements of our split-population model are presented informally in the $2 \times 2$ matrix of Figure 2. The horizontal axis denotes the population of employables and unemployables, denoted by $\mathrm{E}$ and $\hat{\mathrm{E}}$, respectively. Employables are those individuals who may transition from unemployment (U) to employment $(\mathrm{E})$, and whom we therefore term $U-E$ movers. Unemployables are those persons who will never transition from unemployment to employment, and are referred to as $U$-E stayers. On the vertical axis is given the population of those who either consider or rule out the option of labor market withdrawal, respectively I and $\hat{\mathrm{I}}$. They will be termed U-I movers and U-I stayers. (By analogy with the biostatistical literature, E and I may also be termed employment and inactivity susceptibles, while $\hat{\mathrm{E}}$ and $\hat{\mathrm{I}}$ can be said to represent the population of employment and inactivity immunes.)

Those individuals in the first cell of the figure may find employment or instead select inactivity; in either case they represent movers, U-E and U-I movers. Those in the second, bottom-left cell will ultimately find employment but by definition never enter inactivity; in this sense they are respectively U-E movers and U-I stayers. The U-E 
hazard function to be estimated is corrected estimated across these two cells or populations. As for the third, top-right cell this comprises U-E stayers (or employment immunes), and U-I movers (or inactivity susceptibles), who will ultimately move into that destination state. The inactivity hazard function is properly estimated over the first and third cells. Finally, the fourth cell is made up of the long-term unemployed, or more accurately the permanently unemployed who are U-E and U-I stayers (or employment immunes and inactivity immunes). In other words, for individuals to stay in the unemployment state forever requires that they are defective in two respects, both in terms of the transition from unemployment into employment and also the unemployment to inactivity transition. Clearly, if the latent hazards are independent, the probability of never leaving the unemployment spell is just the product of the probability of being a UE stayer with the probability of being a U-I stayer.

In the present paper, we will seek to test for the presence of defective risks such as might result from a random process of unlucky draws and defective risks produced by two very different populations. To effect this comparison, we will first deploy a simple fourth order polynomial baseline hazard function. The basis of the test of the unlucky draws scenario is based simply on the distribution parameters. The basis of the test of the split-population model is a specification that uses the same polynomial baseline hazard but which allows the regressors to affect the population of stayers and not simply the escape rates from unemployment of employment and inactivity movers. In both cases, a correction for unobserved individual heterogeneity is provided. The split-population model is then further refined to allow of a more flexible baseline hazard function in the form of a (13-segment) piecewise constant hazard. Finally, since we have no guidance as to proportionality or otherwise, we also estimate a discrete change specification for the impact of the regressors.

The plan of the paper is as follows. Section II introduces the Portuguese data set and offers a modicum of detail on that country's labor market. Section III offers a formal presentation of the methodology. Detailed presentation of our findings is provided in section IV. A summary drawing together the threads of the preceding arguments concludes. 


\section{Data}

Our data are taken from the nationally representative Portuguese quarterly employment surveys (Inquérito ao Emprego), conducted by the National Institute of Statistics (INE) (Instituto Nacional de Estatistica). The sample period is 1992(2) -1997(4), the starting date being dictated by changes in survey design after the first quarter of 1992 .

The quarterly survey has a quasi-longitudinal capacity. One sixth of the sample rotates out each quarter, allowing us to track transitions out of employment for up to five quarters. Transition rates are obtained by identifying those unemployed individuals in the survey, and their elapsed duration in a given quarter, who move out of employment over the subsequent quarter. The destination states of previously unemployed individuals can also be identified. For present purposes we shall distinguish between the two destination states of employment and inactivity. ${ }^{3}$ We note in passing that that the employment survey is similar to other labor force surveys in providing a snapshot of the stock of unemployed at two moments in time, in this case separated by a quarter. Familiarly, remaining duration of unemployment of those who do not transition out of unemployment has to be inferred. Registed elapsed unemployment duration is top-coded for individuals with 98 months of unemployment or more, though this is a very small propotion of the sample (amounting to less than 1 percent).

Each survey provides information on the length of the current unemployment spell in months and the unemployment benefit status of the worker. It is also possible to track time to exhaustion of benefits. Although we do not exploit the latter information here, instead using access to unemployment benefits (both unemployment insurance proper and means-tested unemployment assistance), note that the seven-element structure of the our age regressor is designed exactly to mimic the stepped increases in benefit entitlement with age. To all intents and purposes, the replacement rate is fixed in Portugal (at 65 percent). Neither it nor the duration of unemployment insurance benefits, which is exclusively age determined, changed over the sample period. ${ }^{4}$

In addition to access to benefits and age, the employment survey contains information on a number of other variables that may be expected also to shift the baseline hazard up or down. Those selected in the present paper are level of schooling, marital 
status, tenure on the job, whether the individual is a new entrant, and the reason for job loss leading to the unemployment event. The local unemployment rate, derived from a source other than the employment survey, was also allowed to shift the baseline hazard function(s).

Since we wish to account for defective risks, each of the above arguments specific to the individual (namely, age, receipt of benefits, schooling, tenure on the last job, and marital status) plus the unemployment rate were used to estimate the split-population regression equations. The general point is that we are interested in considering the factors that affect the probability of being a long-term survivor. Age is expected to be critical in this regard, and is now expressed in continuous form rather than as a grouped variable. Unemployment benefits and the local unemployment rate are also of especial interest: the former because it is the key policy variable, and the latter because it is expected to inform on discouragement.

The sole restrictions placed on the data were that the individual be unemployed at the time of the quarterly survey, male, aged between 16 and 64 years, and resident in mainland Portugal. Given the possibility of sample attrition, we also ensured that individuals appearing in contiguous surveys with the same identifier were in fact the same individual. The sample size is 9,451 individuals. Descriptive statistics are provided in Appendix Table 1.

Over the course of the sample period, the Portuguese unemployment rate rose by almost two-thirds (from 4.1 percent in 1992 to 6.7 percent in 1997). The mean (elapsed) duration of unemployment increased continuously (from 12.2 months to 16.5 months) and, not surprisingly, the distribution of unemployment changed fairly profoundly. In particular, the share of long-term unemployment (12 months or more) rose by almost 74 percent (from 24.9 to 43.3 percent). Note that the proportion of workers covered by the unemployment benefit system has changed little since 1993, and also that the maximum duration of benefits and the replacement rate rules were unchanged over the entire sample period.

Since 1997 the unemployment rate has improved materially and currently approximates the U.S. value. Nevertheless, the scale of the long-term unemployment problem persists. Moreover, Portugal continues to be regarded as the exemplar of a 
sclerotic labor market, with the highest level of employment protection in OECD countries (see OECD, 1999). Furthermore, it has continued to be dogged by what has been termed a "stagnant pool" of unemployment (Blanchard and Portugal, 2001, p. 187), with lows flows in and out and (the corollary) long unemployment duration (see also Bover, García-Perea, and Portugal, 2000). This, then, is the backdrop to the present empirical inquiry.

\section{Methodology}

\section{Two simple hazard models}

A critical concept in statistical analysis of a duration phenomenon is the hazard function. In the study of unemployment duration, the hazard function gives the instantaneous probability of exiting unemployment at $t$, given that the individual stayed unemployed until $t$

$$
h(t)=\lim _{\Delta t \rightarrow 0} \frac{P(t \leq T<t+\Delta t T \geq t)}{\Delta t}=\frac{f(f)}{1-F(t)}=\frac{f(t)}{S(t)},
$$

where $f(t)$ is the probability density function, $F(t)$ is the distribution function, $S(t)$ is the survival function. A useful function is the integrated hazard function

$$
\Lambda(t)=\int_{0}^{t} h(u) d u
$$

which relates to the survivor function simply by

$$
S(t)=e^{-\Lambda(t)}
$$

In this paper we consider two flexible forms for the hazard function. The first is a

fourth order polynomial hazard function

$$
h(t)=\alpha_{0}+\alpha_{1} t+\alpha_{2} t^{2}+\alpha_{3} t^{3}+\alpha_{4} t^{4} . \quad \alpha_{0} \geq 0
$$

Without further restrictions, the polynomial hazard function may lead to an integrated hazard function that converges to a finite value as $\mathrm{t}$ goes to $\infty$, and thus to a defective 
distribution. This will happen if the last (in our case, the fourth) order term is negative. The second is a piecewise-constant hazard function

$$
h(t)=\left\{\begin{array}{lll}
e^{\lambda_{1}} & \text { if } & 0 \leq t<c_{1} \\
e^{\lambda_{2}} & \text { if } & c_{1} \leq t<c_{2} \\
e^{\lambda_{3}} & \text { if } & c_{2} \leq t<c_{3} \\
\cdot & & \\
\cdot & & \\
e^{\lambda_{m-1}} & \text { if } & c_{K-1} \leq t
\end{array},\right.
$$

where the time axis is divided into $K$ intervals by points $c_{1}, c_{2} \ldots, c_{K-1}{ }^{5}$ For the piecewise-constant model, a non-proper distribution is precluded since the hazard rate is positive for the last (open-ended) interval.

\section{A two-destination model}

In this paper we shall also distinguish between two exit modes out of unemployment: employment and inactivity. Thus, we define cause-specific hazard functions to destination $j$

$$
h_{j}(t)=\lim _{\Delta t \rightarrow 0} \frac{P(t \leq T<t+\Delta t T \geq t \mid J=j)}{\Delta t}, \quad \mathrm{j}=1,2
$$

which yield the aggregate hazard function

$$
h(t)=\sum_{j=1}^{2} h_{j}(t)
$$

and the survivor function

$$
S(t)=\prod_{j=1}^{2} S^{j}(t)
$$

where $S^{j}(t)=e^{-\Lambda^{j}(t)}$, and $\Lambda^{j}(t)=\int_{0}^{t} h_{j}(u) d u$.

The model has a conventional competing risks interpretation. In this framework, a latent duration $\left(T_{j}\right)$ unemployment attaches to each exit mode. We only observe the minimum of each latent variable. If risks are assumed to be independent, with continuous 
duration, this model simplifies to two separate single-cause hazard models (but see below). ${ }^{6}$

\section{Proportional hazards specification}

A common way to accommodate the presence of observed individual is to specify a proportional hazards model

$$
h_{j}(t ; x)=h_{0 j}(t) e^{x^{\prime} \beta_{j}} .
$$

where $h_{0 j}(t)$ denotes the baseline specific hazard function, that is, the hazard function corresponding to null values for the covariates $x$. In this case, the covariates affect the hazard function proportionally (i.e. $\frac{d h(x)}{d x_{k}}=\beta_{k} h(x)$ ). An implication of this assumption is that impact of the covariates does not change (in relative terms) with the progression of the spell of unemployment. We shall return to the discussion and test of this restriction below.

\section{Discrete duration model}

Our information on elapsed duration of unemployment is grouped into monthly intervals (while transitions can solely be identified over a fixed interval of 3 months). Let $M=m$ denote the occurrence of an exit in a given month $\left[c_{t-1}, c_{t}\right)$, where $m$ is the realization of a discrete random unemployment duration variable $M \in(1, \ldots, K)$. The probability that an event occurs in the $m^{\text {th }}$ interval (i.e. that an exit occurs over the course of the 3-month window), and that such an exit is to destination $r$, will be given (neglecting, for the sake of parsimony, the $t$ and $x$ indexes) by

$$
f_{m}^{r}=\frac{S_{m-3}^{r}-S_{m}^{r}}{S_{m-3}^{r}} S_{m-3}=h_{m}^{r} S_{m-3}
$$

The functions $f_{m}^{r}$ and $\left(1-S_{m}^{r}\right)$ provide a convenient characterization of the probability density and the cumulative functions associated with the marginal distribution for each latent duration, $T_{j}$, in terms of the specific hazard function $h_{m}^{r}$. A censored 
observation (i.e. a spell of unemployment that is still in progress after the 3-month window) occurs with probability $S_{m}=\prod_{j=1}^{2} S_{m}^{j}$, which is simply the product of the two specific 'survivor' functions.

\section{Observation over a fixed interval}

Apart from the discrete nature of the unemployment duration data, we need to pay attention to the type of sampling plan being used in order to avoid the length bias sampling problems induced by stock sampling (Flinn, 1986). Recall that in our sample the stock of unemployed individuals is observed over a fixed interval of 3 months. In other words, at the time of the first survey the elapsed duration of unemployment is recorded. Three months later, the labor status of the same individual is observed, providing us with information on whether he or she had left unemployment and, if so, the destination state (employment or inactivity). With this sample plan, we need to condition on elapsed duration at the time of the first interview in order to recover the entrant density function (Lancaster, 1990, p. 183). The likelihood contribution for a single individual is given by

$$
L(\theta \mid t, j, x)=\left\{\prod_{m=1}^{K-1} \prod_{j=1}^{2}\left[\frac{S_{m-3}^{j}-S_{m}^{j}}{S_{m-3}^{j}}\right]^{\delta_{m j}}\right\}\left\{\prod_{m=2}^{K}\left[\frac{S_{m}}{S_{m-3}}\right]\right\}^{1-\delta_{m}},
$$

where $\theta$ is a vector of parameters that include regression coefficients and baseline hazard parameters, and $\delta_{m j}$ is an indicator that assumes the value 1 if the individual exits to destination $j$ during the $m^{\text {th }}$ interval, and 0 otherwise. The indicator $\delta_{m}=\sum_{j=1}^{2} \delta_{m j}$ identifies completed durations, so that, $1-\delta_{m}$ equals 1 for a censored observation. Notice that, after 
conditioning on having survived until $m-t$, the $S_{m-3}$ term cancels out for completed durations. The contribution to the likelihood function from a censored observation is simply the product, conditional surviving up to $m-3$, of the two specific survival terms $\left(\prod_{j=1}^{2} S_{m}^{j}\right)$, that is, the probability of not exiting to either employment or inactivity.

\section{Unobserved Individual Heterogeneity}

We also attempt to accommodate the presence of unobserved individual heterogeneity by assuming, as conventional, a multiplicative error term associated with each specific hazard function

$$
h_{j}(t ; x)=h_{0 j}(t) e^{x^{\prime} \beta_{j}} v_{j} .
$$

We further assume that the errors $v_{\mathrm{j}}$ are gamma distributed with mean 1 and variance $\sigma_{j}^{2}$ and are uncorrelated. ${ }^{7}$

We proceed by redefining the specific "survivor" function using the well-known result for gamma mixtures $\bar{S}_{m}^{j}=\left(1+\sigma_{j}^{2} \Lambda_{m}^{j}\right)^{-1 / \sigma_{j}^{2}}$ (see Lancaster, 1990, p.66). After this transformation, the likelihood function is derived as for (11) above

$L\left(\theta, \sigma^{2} \mid t, j, x\right)=\left\{\prod_{m=1}^{K-1} \prod_{j=1}^{2}\left[\frac{\left(1+\sigma_{j}^{2} \Lambda_{m-3}^{j}\right)^{-1 / \sigma_{j}^{2}}-\left(1+\sigma_{j}^{2} \Lambda_{m}^{j}\right)^{-1 / \sigma_{j}^{2}}}{\left(1+\sigma_{j}^{2} \Lambda_{m-3}^{j}\right)^{-1 / \sigma_{j}^{2}}}\right]^{\delta_{m j}}\right\}\left\{\prod_{m=2}^{K} \coprod_{j=1}^{2}\left[\frac{\left(1+\sigma_{j}^{2} \Lambda_{m}^{j}\right)^{-1 / \sigma_{j}^{2}}}{\left(1+\sigma_{j}^{2} \Lambda_{m-3}^{j}\right)^{-1 / \sigma_{j}^{2}}}\right]\right\}^{1-\delta_{m}}$

\section{Split-population model}

Up to this point we have assumed that all destination states are viable ex ante. In other words, even though we allow for the possibility of infinite duration via a non-proper distribution (for given parameters of the polynomial hazard function), until now we neglected the existence of stayers. That is, we have assumed that with respect to transitions to both employment and inactivity all individuals were (potential) movers. We now have to account for the possibility that certain or all choices may be ruled out. This approach has been used in the econometric literature in the context a 'split-population' framework for a single risk (Schmidt and Witte, 1989). ${ }^{8}$ 
In the context of a grouped duration model, a straightforward way to incorporate the possibility of defective risks is to redefine the specific "survival" function as $\tilde{S}_{m}^{j}=1-P_{j}+P_{j} S_{m}^{j}$, where $\mathrm{P}_{\mathrm{j}}$ is the proportion of movers associated with destination $j$. Thus, the 'survival' probability is given by the proportion of $j$ stayers, $\left(1-\mathrm{P}_{\mathrm{j}}\right)$, who do not exit into destination $\mathrm{j}$ with probability 1 , plus, the proportion of movers, $\mathrm{P}_{\mathrm{j}}$, multiplied by the corresponding probability of transition into $j$ at $m, S_{m}^{j}$.

Taking $P_{j}$ as additional unknown parameters to be estimated, the new paramaterization of the specific "survivor" function can be employed in a likelihood function identical to (11). In order to guarantee that $P_{j}$ lies between 0 and 1 , we employ the logit reparameterization for $P_{j}=\exp \left(\mu_{j}\right) / 1+\exp \left(\mu_{j}\right)$. This use of a logit link function is inconsequential in terms of finding evidence of stayers since it does not preclude the possibility of $P_{j}$ being as close to 1 (or zero) as needed.

A natural extension of this model is to allow $P_{\mathrm{j}}$ to depend on a set of regressors $z$, leading to an extended logit link function $P_{j}=\exp \left(\mu_{j}+z^{\prime} \gamma_{j}\right) / 1+\exp \left(\mu_{j}+z^{\prime} \gamma_{j}\right)($ see Yamaguchi, 1992). That is, we can again use the structure of equation (11) to specify the likelihood function

$$
L(\theta \mid t, j, x)=\left\{\prod_{m=1}^{K-1} \prod_{j=1}^{2}\left[\frac{P_{j}\left(S_{m-3}^{j}-S_{m}^{j}\right)}{1-P_{j}+P_{j} S_{m-3}^{j}}\right]^{\delta_{m j}}\right\}\left\{\prod_{m=2}^{K} \prod_{j=1}^{2}\left[\frac{1-P_{j}+P_{j} S_{m}^{j}}{1-P_{j}+P_{j} S_{m-3}^{j}}\right]\right\}^{1-\delta_{m i}},
$$

where $\theta$ now represents the vectors $\beta_{j}, \mu_{j}, \gamma_{j}$, and the baseline hazard parameters. A censored observation results from the interplay of being an U-E stayer (namely, 1-P $\mathrm{P}_{1}$ ), being an U-I stayer (1- $\left.\mathrm{P}_{2}\right)$, being an U-E mover and not exiting to $\mathrm{E}\left(P_{1} S_{m}^{1}\right)$, and being an U-I mover and not exiting to I $\left(P_{2} S_{m}^{2}\right)$. The probability of observing an incomplete duration will be given by the product of the probabilities of not exiting to employment (being an U-E stayer plus being a survivor U-E mover) and not exiting to inactivity (being an U-I stayer plus being a survivor U-I mover).

\section{Split population and unobserved individual heterogeneity}


In order to account for both defective risks and gamma heterogeneity, we employ the transformation $\hat{S}_{m}^{j}=1-P_{j}+P_{j}\left(1+\sigma_{j}^{2} \Lambda_{m}^{j}\right)^{-1 / \sigma_{j}^{2}}$. In short, inserting this definition into equation (11) we define the following likelihood function

$$
\begin{aligned}
& L\left(\theta, \sigma^{2} \mid t, j, x\right)=\left\{\prod_{m=1}^{K-1} \prod_{j=1}^{2}\left[\frac{P_{j}\left(\left(1+\sigma_{j}^{2} \Lambda_{m-3}^{j}\right)^{-1 / \sigma_{j}^{2}}-\left(1+\sigma_{j}^{2} \Lambda_{m}^{j}\right)^{-1 / \sigma_{j}^{2}}\right)}{\left(1-P_{j}+P_{j}\left(1+\sigma_{j}^{2} \Lambda_{m-3}^{j}\right)^{-1 / \sigma_{j}^{2}}\right.}\right]^{\delta_{m j}}\right\} \times \\
& \left\{\prod_{m=2}^{K} \prod_{j=1}^{2}\left[\frac{\left(1-P_{j}+P_{j}\left(1+\sigma_{j}^{2} \Lambda_{m}^{j}\right)^{-1 / \sigma_{j}^{2}}\right)}{\left(1-P_{j}+P_{j}\left(1+\sigma_{j}^{2} \Lambda_{m-3}^{j}\right)^{-1 / \sigma_{j}^{2}}\right.}\right]\right\}^{1-\delta_{m}} .
\end{aligned}
$$

In this case, there are two sources of unobserved heterogeneity competing with each other to account for unforeseen factors. On one hand, there is a distinction between movers and stayers, in term of both employment and inactivity. On the other hand, conditional on being a mover, there is an error term in the specific hazard function that accounts for omitted variables.

Finally, we note that the ML routine from the econometric package TSP (Time Series Processor) was employed to obtain the maximum likelihood estimates. In each case, starting values from a simple single risk specification were used

\section{Findings}

Results of fitting the basic competing risks model, assuming a fourth order polynomial hazard function are provided in the first two columns of Table 1 . The first point to note is that there is no evidence that the duration marginal distributions are defective. Thus, for transitions into employment, the coefficient estimate of the quartic term is (statistically) greater than zero, so that the integrated hazard converges to infinity as $t$ goes to infinity. For transitions into inactivity, the quartic coefficient estimate although negative is not statistically different from zero. Indeed, for this destination state the linear, quadratic, and cubic terms are uniformly insignificantly different from zero, only the constant term being statistically significant at conventional levels. The baseline hazard functions for employment and inactivity are presented in panels (a) and (b) of Figure 3. Both functions are well behaved. The employment hazard is decreasing over a large portion of the 
relevant range (the data are top-coded at 99 months). For its part, the inactivity hazard never approaches zero over the relevant range. Furthermore, one would not reject the null hypothesis of constant (exponential) hazard function for this destination state (chisquare (4) $=3.58 ; \mathrm{p}=0.466$ ).

(Table 1 and Figure 3 near here)

Continuing with the basic model, it is clear that there are differences in the regression coefficient estimates across destination states. The notable exception is the effect of access to unemployment benefits, the effect of which is in each case to reduce transitions rates out of unemployment by approximately 43 percent. Older workers have markedly lower transition rates into employment than their younger counterparts, while younger workers have noticeably lower transitions into inactivity. Familiarly, being married increases escape rates into employment, although the negative effect on inactivity transitions is not statistically significant. Labor market entrants exhibit reduced flows into employment vis-à-vis the reference category - those that are unemployed for reasons of individual dismissal or voluntary exit - and correspondingly higher flows into inactivity. Not surprisingly, among their more experienced counterparts, those who entered unemployment following the termination of a fixed-term contract have noticeably higher escape rates into employment. Somewhat surprisingly, however, there is a clear indication that higher unemployment decreases transitions into inactivity - and its impact on employment transitions is muted - which would suggest that there is no discouragement effect from labor market slack, or that there is an offsetting income effect. Equally, there are no signs that workers entering unemployment by reason of a mass layoff subsequently return to employment at higher rates than do individual separations.

Results of implementing the parametric correction for unobserved individual heterogeneity are shown in the third and fourth columns of Table 1. Note that although the sigma coefficient estimates are well determined, the correction does not yield any substantive changes on the earlier results. But there is clear suggestion of higher (error) variance in the case of employment transitions and, more generally, the regression coefficient estimates increase in absolute magnitude as well as in their imprecision. The coefficient estimates for the polynomial hazard functions again fail to indicate that the 
marginal duration distribution is defective for either the employment or the inactivity transitions.

We take this evidence as suggesting that, within this type of specification, latent infinite durations are not present in the data. In other words, an individual does not face a non-zero probability of drawing an infinite duration. At this point, we therefore end our discussion of non-proper distributions and in what follows focus our attention on the split-population (or mover-stayer) alternative characterization. This, of course, does not preclude the use of a polynomial hazard function. It just happens that the estimation results appear to suggest that defective risks are present via the heterogeneity of the underlying sub-populations in our sample. The nature of this heterogeneity is simply the distinction between the sub-population of individuals who would always ultimately transition to a given destination state, and those would never make that transition.

The split-population model is presented in the last two columns of Table 1, again assuming a polynomial specification for the distribution function and correcting parametrically for unobserved individual heterogeneity. There is strong evidence of defective risks. Beginning with employment transitions, three variables - age, access to unemployment benefits, and schooling - increase the probability of being a U-E stayer (or employment-immune), while marital status significantly reduces that probability. With the exception of the perverse schooling effect, these results seem sensible. We shall have occasion to revisit the schooling result below.

The estimated proportion of U-E stayers (or non-employables) depends very heavily upon age. Thus, for the population of 35 year-olds (i.e. the mean age) possessing average values of the other characteristics, 5.3 percent of unemployment benefit recipients are employment immunes or stayers, as compared with just 1.3 percent of nonrecipients. But for the population of 50 year-old unemployment benefit recipients no less than 48.2 percent fail to secure acceptable job offers, and the corresponding proportion for nonrecipients rises to 18.3 percent. (The basis of these calculations are as follows. The $\mu$ coefficient estimate, or constant term, informs us that on average exp $4.301 /(1+\exp 4.301)$ or 98.7 percent of the unemployed population are employables, so that 1.3 percent are employment immunes. For unemployment benefit recipients, exp $(4.301-1.424) /(1+\exp (4.301-1.424))$ or 94.7 percent are employables, and thus 5.3 
percent are employment immunes. Introducing age, since 35 years is the mean age, the proportions of immunes or employment stayers among recipients and nonrecipients are unchanged at 1.3 percent and 5.3 percent respectively. The proportion of employables among the 50 year old population for nonrecipients is exp $(4.301-15(.187)) /(1+\exp$ (4.301 - 15(.187)), yielding the 18.3 percent immune value; for recipients the calculation for employables is $\exp (4.301-1.424-15(.187)) /(1+(4.301-1.424-15(.187))$, thus yielding the immune proportion of 48.2 percent.)

It appears that the main effect of age on transitions from unemployment into employment works through the increase in the proportion of U-E stayers (or employment immunes) rather than through a reduction in the hazard rate of the employment mover population. As can be seen in the penultimate column of Table 1, the coefficient estimates for all but the highest age category are now statistically insignificant. Nevertheless, the impact of receipt of unemployment benefits retains its explanatory power after accounting for the presence of employment immunes or stayers. This suggests that there are two mechanisms at work. On one hand, receipt of unemployment benefits increases quite sizably the number of individuals who will never generate an acceptable job offer (that is, increases the number of U-E stayers). On the other hand, one also obtains the more conventional result that access to unemployment benefits decreases transitions into employment; that is, it reduces hazard rates among U-E movers.

Turning finally to transitions from unemployment to inactivity (U-I), shown in the final column of Table 1, it is clear that we are indeed largely sampling from a population that will never transition into inactivity, comprising U-I stayers or inactivity immunes. This is indicated by the low value of the constant term, which implies that no less than 48.2 percent of the unemployed population will never consider inactivity. Of the variables expected to influence the proportion of inactive immunes, only schooling is statistically significant and it operates to prevent flows from unemployment into inactivity. There is evidently a larger portion of individuals among more highly educated groups that never consider the inactivity option.

If one were to sample 35 year-olds possessing (other) average characteristics for the continuous variables and who are assigned reference values for the binary variables, some 34.2 percent of this group would be U-I stayers (or inactivity immunes). This 
proportion is decreasing in age: it is about 44.6 percent for workers aged 20 years, and falls to 25.2 percent for workers aged 50 years.

In general, the coefficients contained in the final column of Table 1 are estimated with less precision than before. In part, this result reflects the combination of a comparatively small number of unemployed individuals entering inactivity $(\mathrm{n}=305$, or 3.2 percent) with a heavily parameterized specification.

(Table 2 near here)

In Table 2 we report parallel results from fitting a 13-segment piecewise-constant baseline hazard function (rather than a fourth order polynomial) to the duration data. Thus, the first two columns of the table give results for the basic competing risk specification; the next two columns supplement this specification with a control for gamma unobserved individual heterogeneity; and the last two columns present the full defective risks specification in which the probability of observing infinite durations (or individuals with zero transition rates - that is, stayers) is allowed to be influenced by six regressors.

The first point to be made is that likelihood ratio tests cannot be used to differentiate between the specifications in Tables 1 and 2 because the models are not nested. Nevertheless, the piecewise-exponential model provides a more flexible representation of the baseline hazard function. We should also note the hazard rate for the final segment of the piecewise-constant - the term that goes from the last knot point to infinity - is strictly positive, implying that the distribution is proper. That is, the integrated hazard function converges to infinity as $t$ goes to infinity. In other words, unlike the polynomial specification, by construction the piecewise-exponential function does not allow individuals to draw infinite durations (the density probability function has no mass point at infinite duration). Long-term (infinite) survivors are possible solely through the presence of stayers.

The regression coefficient estimates for the basic model in the first two columns are remarkably close to the corresponding estimates from the polynomial specification in Table 1, although the positive effect of mass layoffs on the employment hazard is now statistically significant. But some differences emerge with the correction for unobserved individual heterogeneity in the next two columns. Not only are estimates of the error 
terms higher compared with the polynomial specification for both the employment and inactivity equations, but the regression coefficient estimates change markedly and are mostly higher in absolute terms. To take just one example, access to benefits is now associated with a downward deflection of both hazards of around 64 percent (as compared with 50 percent or less).

Turning to the last two columns of Table 2, however, we find that the regression coefficient estimates for the hazard function(s) are now much closer to the polynomial. The major differences between the two concern the regression coefficients for the splitpopulation equation. In particular, the age and schooling coefficient estimates for employment are less sizeable than before in absolute magnitude. Both outcomes seem sensible. As far as the schooling variable is concerned, this is no longer statistically significant; that is, we no longer obtain the troublesome result that those with higher levels of schooling are more likely to be U-E stayers. As far as age is concerned, we would surmise that the use of a more flexible baseline hazard goes some way to 'correcting for' the inverse association between age and schooling level that appears to exaggerate the effect of age on the proportion of U-E stayers in the polynomial specification. In any event, the estimated population of unemployables is much higher than before: 23.1 percent (9.1 percent) for 35 year-old unemployment benefit recipients (nonrecipients), and 51.8 percent (27 percent) for 50 year-old recipients (nonrecipients).

The split-population results for inactivity resemble those obtained for the corresponding polynomial specification in Table 1. Specifically, the estimated proportions of U-I stayers are now: 37 percent (28.7 percent) for 35 year-old unemployment benefit recipients (nonrecipients) and 26.7 percent (19.9 percent) for 50year-old recipients (nonrecipients).

The estimated error variances are still much higher for the piecewise-constant specification vis-à-vis the polynomial counterpart. It appears that the gamma variance estimate is particularly sensitive to the manner in which the upper tail of the distribution of unemployment duration is modeled. Overall, the results for the piecewise constant variant of the split-population model seem to be more convincing than for the polynomial, we shall use the former estimates to further address the critical role of age and unemployment benefits in affecting hazard rates and defective risks and to illustrate 
the bias toward negative duration dependence that arises from choice of an inappropriate population.

But before proceeding, we need briefly to consider the assumption of proportionality. In Appendix Table 2, we re-estimate the split-population model for both the polynomial and piecewise-constant specifications assuming a discrete break in the effect of the regressors on hazard rates after 6 months of unemployment. The choice of 6 months is essentially arbitrary, though it does of course coincide with the onset of one conventional definition of long-term unemployment. In reading this table, note that the estimates given in the second, fourth, sixth and eighth columns refer to the change in the corresponding coefficient estimate in the preceding column. Among other things, it can be seen that allowing for a discrete change in covariate effect calls into question the proportionality assumption with respect to some covariates, but not the notion of defective risks. But, as a practical matter, we do not reject the null hypothesis of no discrete change for all the regression coefficients - chi-square (30) is $36.04(p=0.208)$ for the polynomial specification and $32.34(\mathrm{p}=0.356)$ for the piecewise-exponential specification. Perhaps the most noticeable effect of allowing for a discrete change in regression coefficients is to strengthen the negative effect of age for longer durations on the employment hazard for both specifications of the duration of unemployment distribution. Note, too, that use of a flexible baseline parameter leads to the sigma parameter converging to zero in the case of transitions to inactivity, implying that unobserved individual heterogeneity is not present among this population of U-I movers.

(Figures 4 though 7 near here)

The crucial role of unemployment benefits in retarding transitions out of unemployment is now addressed in more detail. Hazard functions by destination state are charted in Figures 4 and 5. The estimates are again based on the defective risks model contained the two final columns of Table 2. Note that the hazards in Figures 4 and 5 are unconditional, and use average values of the variables in their construction; that is, they also reflect the presence of stayers on transition rates. Since the hazard functions depicted in the figures reflect the representation of a sub-population of individuals evincing zero escape rates, the effect will be to drive down the hazard rates and produce a tendency towards negative duration dependency because the sample will be made up with an 
increasingly proportion of stayers with the passage of time. This effect also implies that the hazard functions will no longer be proportional to each other, even though they retain the proportionality property among movers.

For the employment cause-specific hazard function, there is a tendency for escape rates to fall with jobless duration for both recipients and nonrecipients alike. The decline for nonrecipients is fairly sharp over the first 12 to 18 months of the jobless spell, after which point the decline is modest, with a slight uptick after the twenty-fifth month. For recipients, the decline is both more muted and shorter lived. (Figure 7 makes the purely technical point that, if there were no U-I stayers, the employment cause-specific hazard function for non-recipients would indicate a rise in escape rates a little after twelve months into the jobless spell. Although not presented graphically, the same result obtains for unemployment benefit recipients.).

Transitions into inactivity in Figure 5 display a quite different pattern. For both nonrecipients and recipients the hazard rises and then falls, peaking at around 12 months for the former and 18 months for the latter. As before, escape rates into inactivity are uniformly higher for nonrecipients than recipients. While we have no cogent explanation for the shape of the hazard function, there is no real indication that transitions into inactivity are an end-state realized after fruitless search for employment. Having said that, as can be seen from Figure 6, the proportion of transitions into inactivity does increase noticeably during the initial 12 months of unemployment. In this regard, differences between recipients and non-recipients are muted, both functions peaking at a little under 30 percent after 18 months.

(Figures 8 and 9 near here)

Aggregate survival functions and cause-specific 'survival' functions for the two destination states are given in Figures 8 and 9, respectively. Both are computed from the last two columns of Table 2. That is, the aggregate survival function is simply obtained by the multiplication of the specific 'survivor' functions given by $\hat{S}_{m}^{j}$ above. In short, the survivor rates are determined by both movers and stayers. From Figure 8 it can be seen that estimated median joblessness duration is around 6 months for nonrecipients and over 16 months for recipients, and that defective risks apply. The aggregate survivor function in Figure 8 does not converge to zero. Rather, it converges to $0.106(0.021)$ for 
unemployment benefit recipients (nonrecipients). These values denote the proportions of 'long-term unemployed.' They are simply the product of the proportion of U-E stayers and U-I stayers: $0.370 \times 0.287$ in the case of recipients and $0.091 \times 0.231$ for nonrecipients. Consistent with the information provided earlier on the cause-specific hazard functions, the disaggregated functions in Table 9 make it clear that survival rates for activity are much higher than for employment, and in each case higher for recipients than nonrecipients.

(Figures 10 and 11 near here)

Our analysis has also indicated that age is an important determinant of escape rates out of unemployment. Figures 10 and 11 reconsider the association between age and destination state (see also Table 3, below). The former figure indicates that the proportion of U-E stayers - those who will never receive acceptable job offers - rises with age and in the same manner for recipients and nonrecipients alike. On the other hand, the latter figure demonstrates that the proportion of U-I stayers is decreasing in age. Both effects are reinforcing in the unemployment duration of older workers.

(Table 3 near here)

Finally, in Table 3 we provide some simulations of the effect of unemployment benefits and age on unemployment. First consider survival rates in joblessness aggregated over both destination states. As can be seen from the table, survival rates decline over the jobless spell and increase sharply in age and benefit receipt. The decline in survival rates with duration is more pronounced for nonrecipients than recipients, but age is more important than access to benefits in arresting the decline in survival rates. Notice that the this depressing effect of age on the intensity of transitions out of unemployment is mainly driven by the increase in UE stayers with age and not by the decrease in the hazard rates among U-E movers. Similarly, although the pattern of survival rates at 3, 12, and 36 months points to greater persistence among recipients and older individuals, the increase in survival rates with age always exceeds the corresponding increase in survival rates with benefits. That being said, the impact of benefit receipt is profound; for example, at 
36 months the survival rates of recipients are more than double those of nonrecipients for each of the three age groups.

The entries for defective risks (i.e. either U-E or U-I stayers) show that the proportion of those who never get a job offer rises steadily with age and with benefit receipt by age. Roughly 3 (8) percent of 20 year-old nonrecipients (recipients) will not receive an acceptable job offer, rising to 37 (63) percent in the case of their 50 year-old counterparts. The proportions of those who will never transition into inactivity declines with age and benefit receipt in roughly equal proportion (see also Figure 11).

The estimated median jobless duration values - shown at the foot of the table while again confirming the important role of age and benefits in retarding transitions out of unemployment, make the point that destination state also matters. We present two sets of estimates of median duration. In one case, we admit - as is in practice the case - that an individual can move into either employment or inactivity. This is consistent with a conventional interpretation and statistical definition of unemployment duration. In the other, we simulate a situation where the possibility of entering inactivity is precluded, and compute the length of time it will now take to find employment if inactivity is ruled out, namely, the time needed to find a job. It can be seen that under the latter exclusion, duration would increase from 5 to 7 weeks for a 20 year-old non-recipient and from 11 to 14 weeks for his recipient counterpart. By the same token, duration would rise from 11 to 24 weeks for a 50 -year-old non-recipient. ${ }^{9}$ This type of simulation is straightforward in the framework of an independent competing risks model, where one can easily compute the duration for a given risk (or destination) precluding some or all the other risks. In this case, if inactivity is not possible, the duration of unemployment will be given simply by the U-E specific 'survival' function.

\section{Conclusions}

It is important to underscore the point that defective risks are compatible with a variety of structural models of unemployment. Thus, for example, the hiring model of Blanchard and Diamond (1994), in which would-be employees are ranked by employers on the basis of their jobless duration, implies latent infinite durations because some workers will never get hired. Defectiveness may also arise if individuals rule out certain destinations. 
The obvious analogy here is the worker-firm matching model of Jovanovic (1979), in which some workers are so contented with their job match that they remain employed forever, leading to a defective tenure distribution. In the present paper, we used the organizing device of a polynomial distribution to effect a test of two such sources of defective risks: (a) a model of unlucky draws in which everyone is equally likely to end up permanently jobless, and (b) a model with separate populations of movers and stayers in which defectiveness is produced by the behavior of the latter. On this occasion, the split-population model won out.

Our split-population model provides a compelling explanation for European structural unemployment and the interplay between inactivity and employment. It will be recalled that for individuals to be consigned to the unemployment state forever requires them to be defective in each of two transitions, namely, from unemployment to employment and from unemployment to inactivity. The permanently unemployed are thus the product of two probabilities. Our simulations confirmed that the product is nontrivial, especially when one considers subgroups of the population.

It is also important to emphasize that the likelihood of confronting defective risks increases with the number of destinations (i.e. more states than just employment and inactivity). This possibility considerably extends the reach of this kind of model to a variety of research questions that involve duration analysis, and not solely the study of economies where long-term unemployment is the dominant policy concern. But assuredly, in the context of unemployment analysis, the more dramatic content of the model is likely to obtain in circumstances of protracted long-term unemployment. To repeat, some individuals either as a result of their past choices or current endowments may be permanently jobless.

The statistical advantages of the split-population model are also worth emphasizing. They are basically threefold. In the first place, if defective risks are present, it is obvious that traditional approaches will lead to inconsistent estimates of the hazard regression coefficients. Indeed, it was shown that some regression coefficient estimates for example, the age coefficients - changed dramatically after taking the presence of stayers into account. In the second place, the shape of the baseline hazard function will be misspecified, biasing the parameter estimates toward negative duration dependence 
because the relative proportion of stayers increase with time. Finally, and no less important, the model allows us to straightforwardly identify factors (i.e. the regression covariates) that influence the presence of stayers. These advantages are achieved at no significant cost because conventional unemployment duration models are special cases of this mover-stayer treatment. Despite its heavy parameterization, the computational burden of estimating the split-population model was surprisingly light. Moreover, the results obtained were plausible and obtained with fairly good precision.

Some other aspects of our analysis might also be noted. The notion that employment and inactivity are two very distinct behavioral states was clearly vindicated in this exercise. It was also interesting to find that the proportion of U-I transitions increased significantly over the course of the unemployment spell. This result may well suggest that discouragement effects are better identified by examining the proportion of transitions (a relative measure) rather than by looking to the shape of the specific hazard function (an absolute measure). For its part, the role of age is critical; not just in retarding escape rates from unemployment but also in elevating the population of employment immunes. The fact that large numbers of older workers are permanently unemployed - up to 13.7 percent (5.2 percent) of 50 year-olds UI recipients (nonrecipients) - is a worrying finding of our analysis. Further study of this issue is urgently required, using structural approaches to investigate whether it is a reservation wage phenomenon or rather, as we suspect, a function of the arrival rate of job offers. As far as unemployment benefits are concerned, their negative effect in slowing transitions out of unemployment and increasing the proportion of long-term unemployed is massive. The effects of age and access to benefits in increasing the proportion of those who will never find work were found to be reinforcing. This conjunction would appear to question the logic of making maximum potential duration of benefits so heavily dependent upon age (or previous tenure, as is widely the case in Europe). There is another issue for policy: if the costs of unemployment are so dramatic for workers (in terms of jobless duration), and firms do not internalize these costs, then a strong case can be made for the introduction of experience rating as a partial offset. Finally, we note that the familiar pro-supply effect of marital status is confirmed in our analysis: being married increases (decreases) the 
employment (inactivity) hazard and reduces the proportion of both types of stayers (i.e. U-E and U-I stayers). 


\section{Endnotes}

1. For an alternative statistical duration model that distinguishes between short- and long-term unemployment, see Portugal and Addison (1995).

2. Thus, for example, none of these studies accommodates the two sources of defectiveness identified in the present paper; neither Pudney and Thomas (1985) nor Melkersson (1999) allow the proportion of stayers to be influenced by observed characteristics; while Yamaguchi does not account for multiple destinations and unobserved individual heterogeneity.

3. For an analysis of job search methods used by unemployed workers that exploits the wider array of destination states contained in the survey, see Addison and Portugal (2000).

4. The maximum duration of unemployment insurance (UI) benefits is 10 months for those aged less than 25 years, and rises in roughly 3-month intervals for each incremental five years of age up to 30 months at 55 years. Individuals need 18 months insured employment during the two years prior to the unemployment event to qualify for UI benefits proper. Means-tested unemployment assistance is paid to those who have only 6 months insured employment and to UI exhaustees. For the former, the maximum duration of these reduced benefits is the same as due under UI, for the latter it is one-half that due under UI; and in both cases this duration is again purely age determined.

5. As noted earlier, we use month as the time calendar unit. In specifying the baseline hazard function, we used three initial intervals of 1 month length, seven subsequent intervals of 3 months' duration, then two intervals of 6 months, and a final, open-ended interval. That is, the knot points are 1, 2, 3, 6, 9, 12, 15, 18, 21, 24, 30, and 36.

6. The approach is rooted in the biostatistics literature, where the context of competing risks is the presence of different diseases. In this setting, one can simulate the effect on the expected life of an individual resulting from the elimination of a single risk/disease (see Cox and Oakes, 1985; Kalbfleisch and Prentice, 1980).

7. Cockx (1997) presents a similar treatment of unobserved individual heterogeneity in the context of competing risks. 
8. See also Pudney and Thomas (1995) for an extension of the split-population model to multiple destinations, and Maller and Zhou (1996) for an exploitation of duration models with long-term survivors.

9. Note that the bottom-right cell entry in Table 3 is undefined for 50 year-old recipients for the simple reason that 63.2 percent of this group fail to receive acceptable job offers. 


\section{References}

Addison, John T. and Pedro Portugal. 2000. "Job Search Methods and Outcomes." Unpublished paper, Department of Economics, University of South Carolina. [Forthcoming in Oxford Economic Papers, 2002.]

Blanchard, Olivier and Peter Diamond. 1994. "Ranking, Unemployment Duration, and Wages." Review of Economic Studies 61 (July): 417-434.

Blanchard, Olivier and Pedro Portugal. 2000. "What Hides Behind an Unemployment Rate: Comparing Portuguese and U.S. Labor Markets." American Economic Review 91 (March): 187-207.

Bover, Olympia, Pilar García-Perea, and Pedro Portugal. 2000. "Labour Market Outliers: Lessons from Portugal and Spain." Economic Policy 31 (October): 381-428.

Cockx, Bart L. W. 1997. "Analysis of Transition Data by Minimum-Chi Square Method: An Application to Welfare Spells in Belgium." Review of Economics and Statistics 79 (August): 392-405.

Cox, D.R. and D. Oakes. 1985. Analysis of Survival Data. London: Chapman and Hall.

Fallick, Bruce Chelimsky. 1991. "Unemployment Insurance and the Reemployment Rate of Displaced Workers." Review of Economics and Statistics 73 (May): 228-235.

Flinn, Christopher J. 1986. "The Econometric Analysis of CPS-Type Unemployment Data." Journal of Human Resources 21 (Fall): 456-489.

Flinn, Christopher J. and James J. Heckman. 1982. "Models for the Analysis of Labor Force Dynamics." In Advances in Econometrics, Vol. 1, edited by R.L. Basmann and G.F. Rhodes. Greenwich, Connecticut: JAI Press, pp. 35-95.

Flinn, Christopher J. and James J. Heckman. 1983. "Are Unemployment and Out of the Labor Force Behaviorally Distinct Labor Market States?" Journal of Labor Economics 1 (January): 28-42.

Han, A., and J. Hausman. 1990. "Flexible Parametric Estimation of Duration and Competing Risks Models." Journal of Applied Econometrics 5 (January-March): 1-28.

Heckman, James J., and Burton Singer. 1985. "Social Science Duration Analysis." In Longitudinal Analysis of Labor Market Data, edited by James J. Heckman and Burton Singer. Cambridge: Cambridge University Press, pp. 39-58. 
Heckman, James J. and James R. Walker. 1990. "Estimating Fecundability From Data on Waiting Times to First Conception." Journal of American Statistical Association 85 (June): 283-294.

Jovanovic, Boyan. 1979. "Job Matching and the Theory of Turnover." Journal of Political Economy 87 (October): 972-990.

Kalbfleisch, J.D., and R.L. Prentice. 1980. The Statistical Analysis of Failure Time Data . New York: Wiley.

Lancaster, Tony. 1990. The Econometric Analysis of Transition Data. Cambridge: Cambridge University Press.

Maller, Ross and Xian Zhou. 1996. Survival Analysis with Long-Term Survivors. Chichester and New York: John Wiley and Sons.

Melkersson, Maria. 1999. "Unemployment Duration and Heterogeneous Search Behavior among Swedish Disabled Workers." Unpublished paper, SOFI, University of Stockholm.

Meyer, Bruce D. 1990. "Unemployment Insurance and Unemployment Spells." Econometrica 58 (July): 757-782.

Narendranathan, Wiji, and Mark B. Stewart. 1993. "Modeling the Probability of Leaving Unemployment: Competing Risks Models with Flexible Base-Line Hazards." Applied Statistics-Journal of the Royal Statistical Society Series C 42 (1): 63-83.

OECD. 1999. Employment Outlook. Paris: Organisation for Economic Co-operation and Development.

Portugal, Pedro and John T. Addison. 1995. "Short and Long-Term Unemployment. A Parametric Model with Time-Varying Effects." Oxford Bulletin of Economics and Statistics 57 (May): 205-227.

Pudney, Stephen, and Jonathan Thomas. 1995. "Specification Tests for the Competing Risks Duration Model: An Application to Unemployment Duration and Sectoral Movement." Oxford Bulletin of Economics and Statistics 57 (August): 323-347.

Ridder, Geert and Gerard van den Berg. 2001. "A Cross-Country Comparison of Labor Market Frictions." Paper presented at the Bank of Portugal Conference Labor Market Institutions and Economic Outcomes, Cascais, June 3-4.

Schmidt, P. and A.D. Witte. 1989. "Predicting Criminal Recidivism Using 'SplitPopulation' Survival Time Models." Journal of Econometrics 40 (January): 141-159.

Sargent, Thomas J. and Lars Ljungqvist. 1998. "The European Unemployment Dilemma." Journal of Political Economy 106 (June): 514-550. 
Yamaguchi, Kasuo. 1992. "Accelerated Failure-Time Regression-Models with a Regression- Model of Surviving Fraction - An Application to the Analysis of Permanent Employment in Japan." Journal of the American Statistical Association 87 (June): 284292. 
Figure 1: Illustration of a Non-Proper Distribution

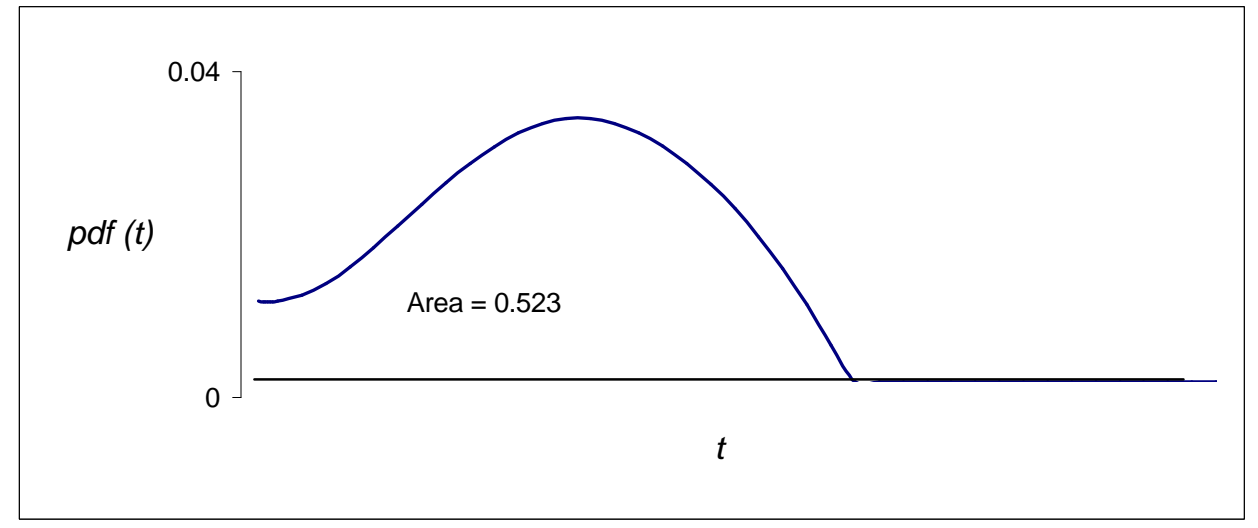

(a) probability density function

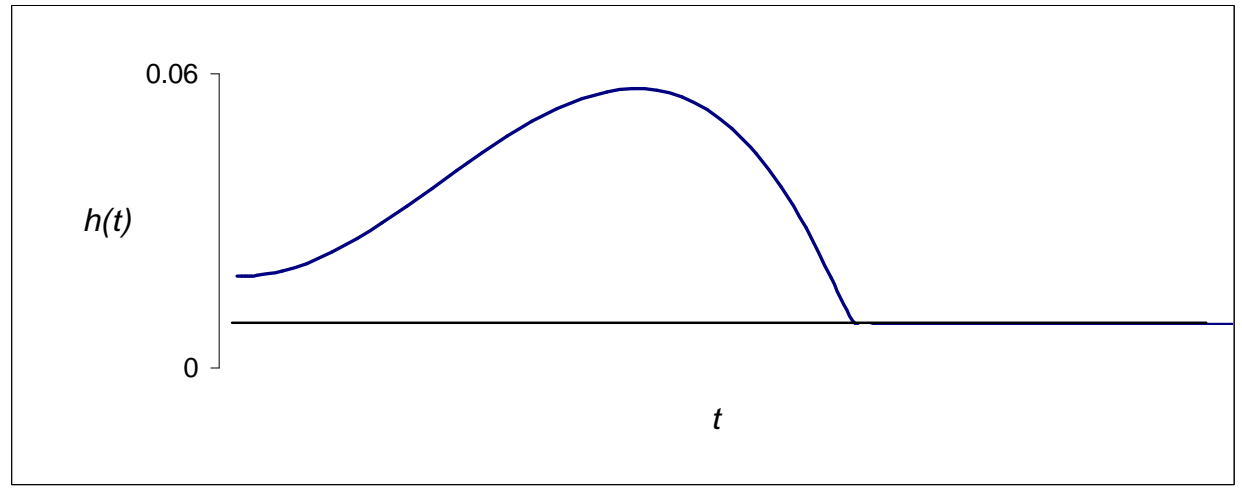

(b) hazard function

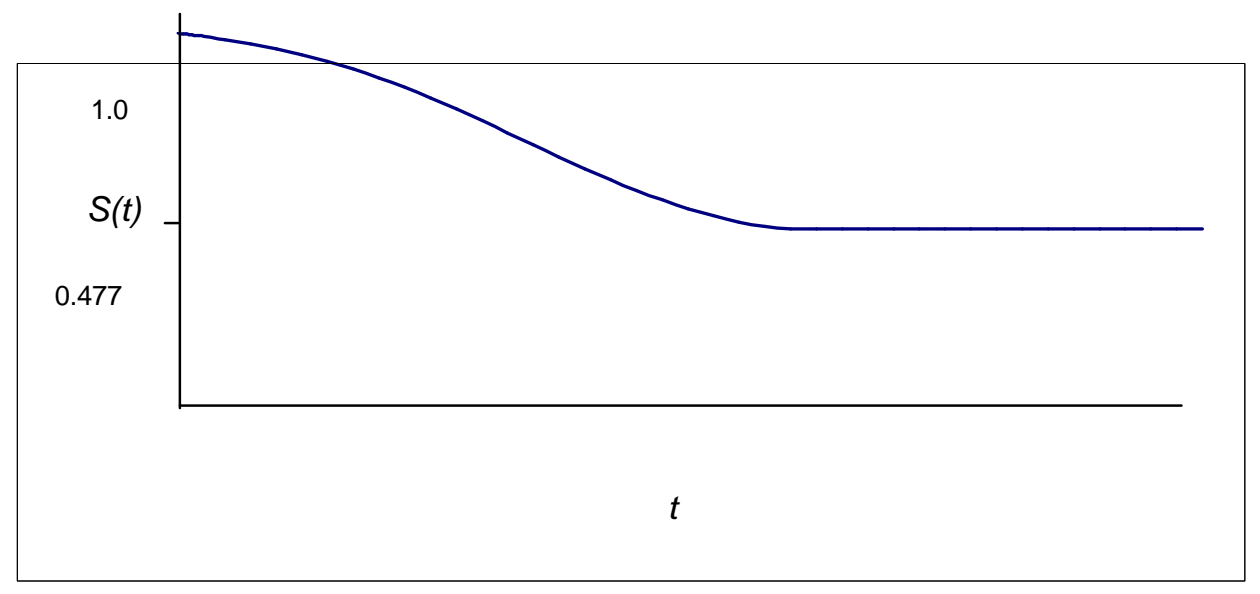

(c) survival function 
Figure 2: Split-Population Typology

Employability

E

$\hat{E}$

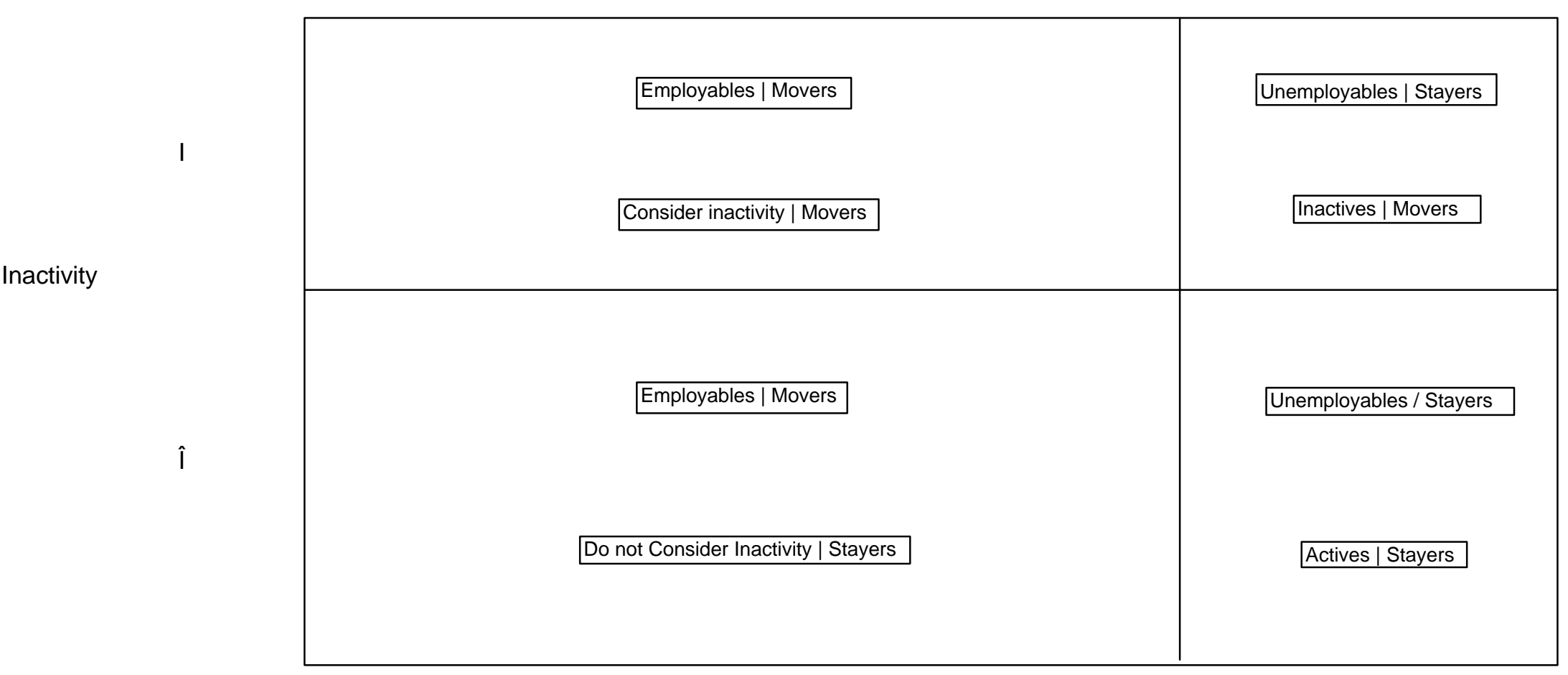


Figure 3: Polynomial Hazard Function

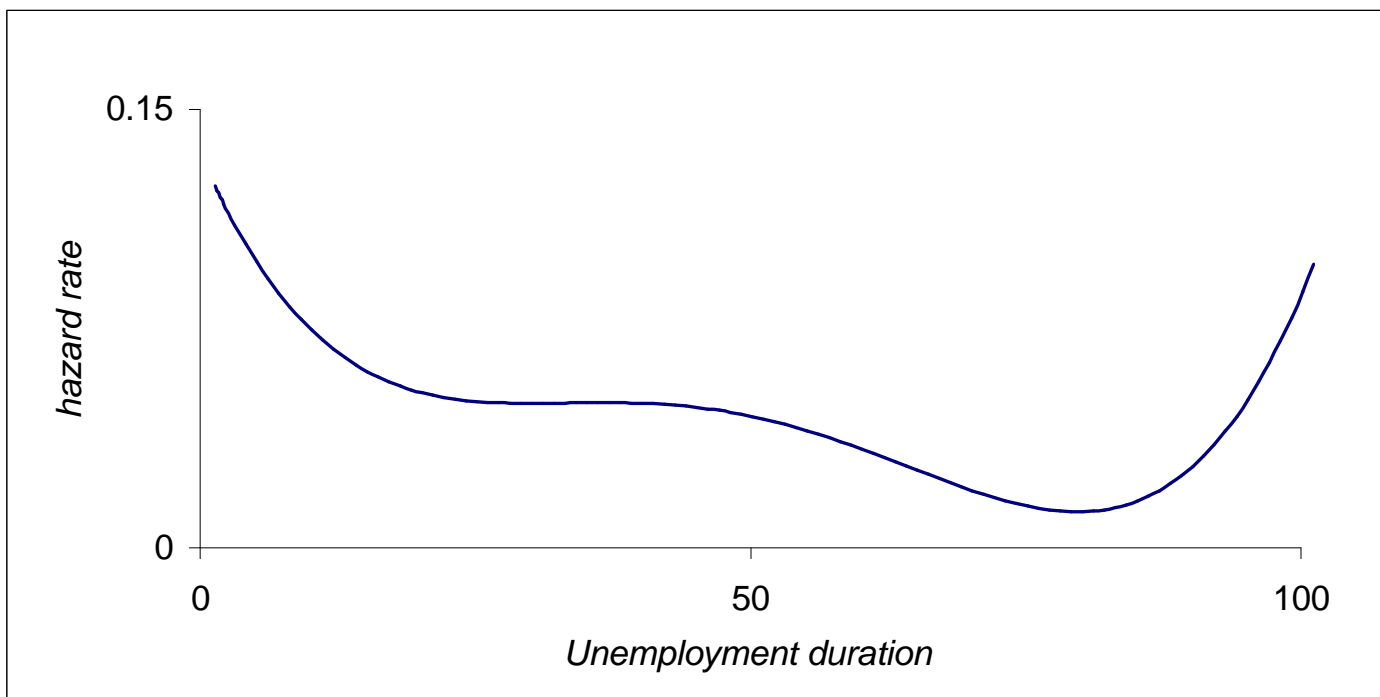

Note: Baseline hazard functiom obtained from Table 1, column 1.

(a) employment hazard function

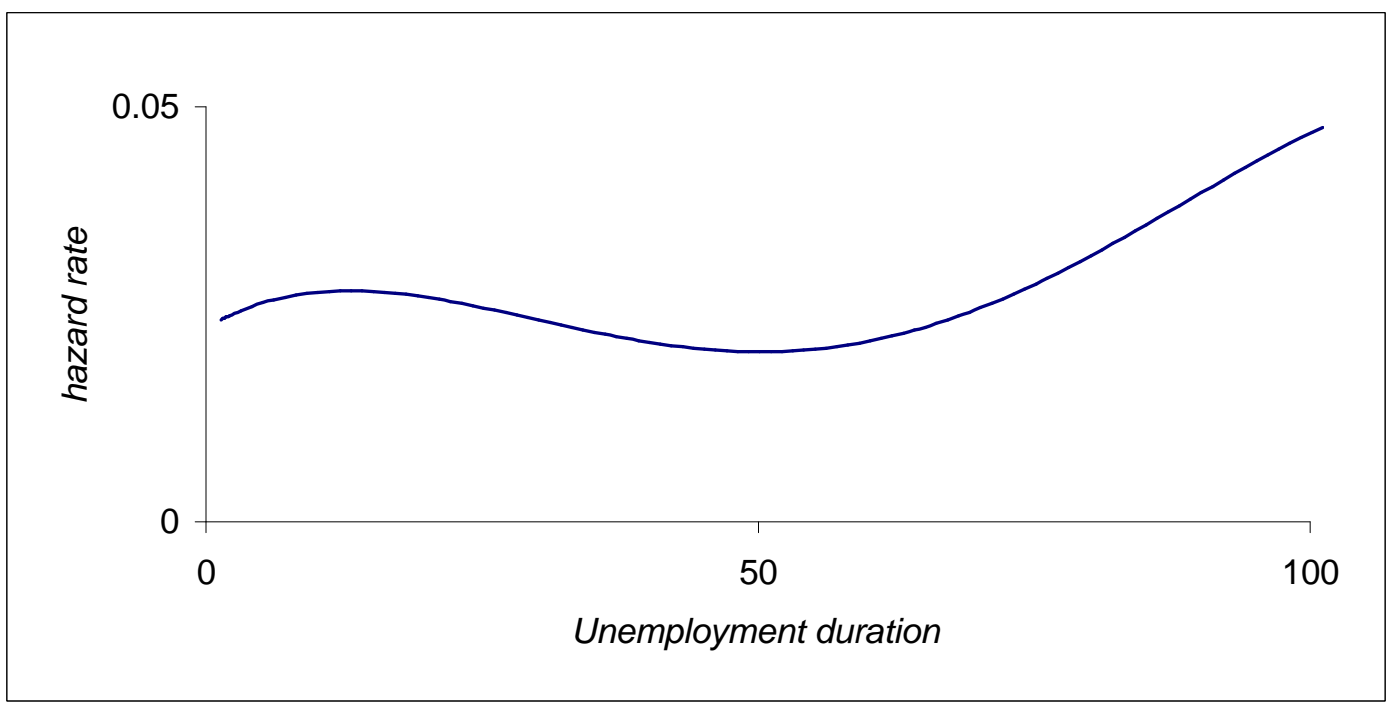

Note: Baseline hazard functiom obtained from Table 1, column 2.

(b) inactivity hazard function 
Figure 4: Cause-Specific Hazard Function - Employment

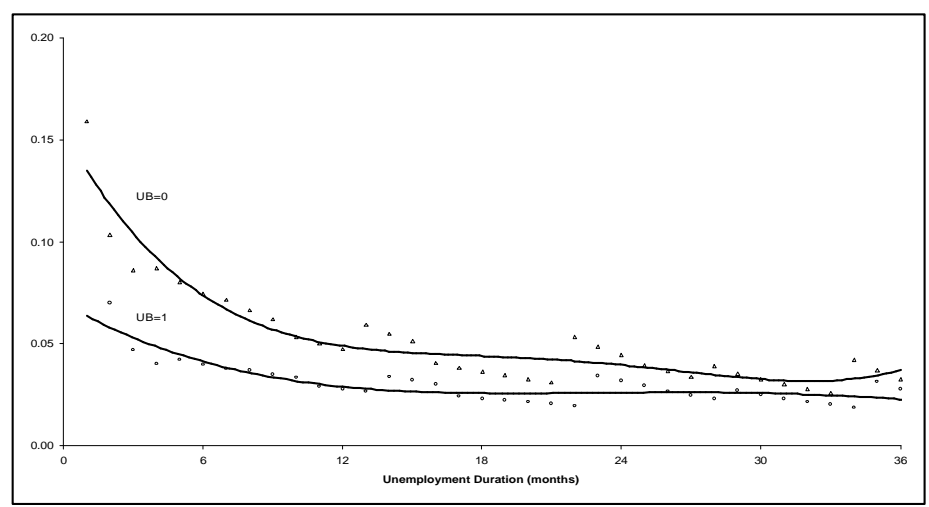

Note : Hazard function obtained from the specification in Table 2, column 5. Hazard functions are unconditional, reflecting the presence of stayers.

Figure 6: Those Moving into Inactivity as a Proportion of all Transitions

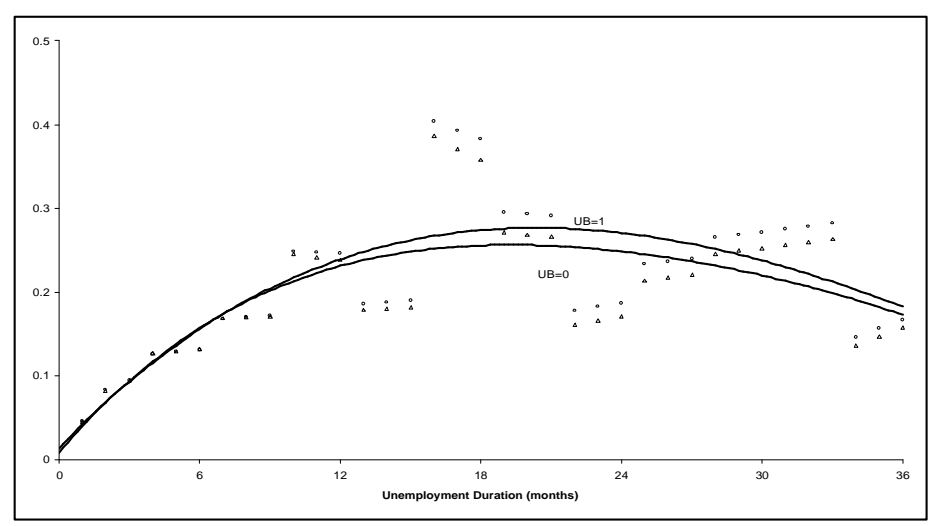

Note: Computed as the the ratio of the inactivity hazard function to the aggregate hazard function (the sum of the two specific hazard functions). Values obtained from the specification in Table 2, columns 5 and 6
Figure 5: Cause-Specific Hazard Function - Inactivity

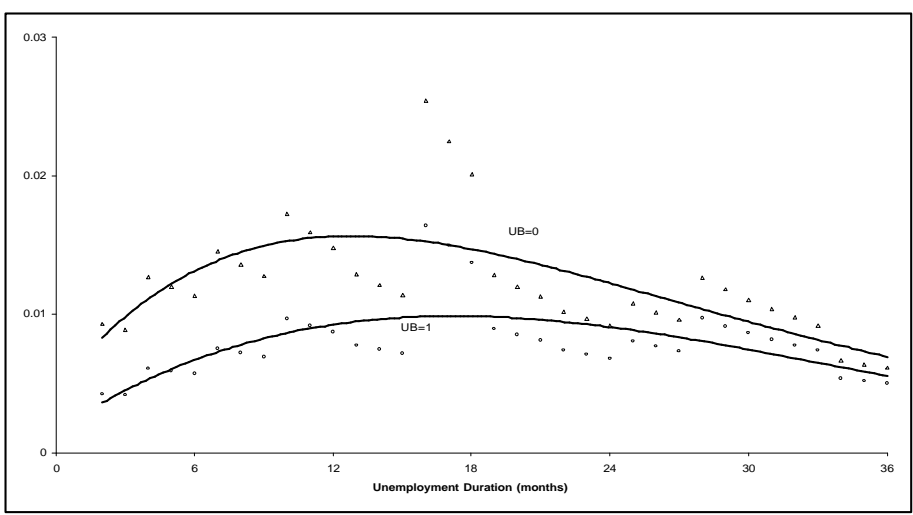

Note : Hazard function obtained from the specification in Table 2, column 6. Hazard functions are unconditional, reflecting the presence of stayers.

Figure 7: Non-recipient Employment Hazard Function with and without Defective Risks

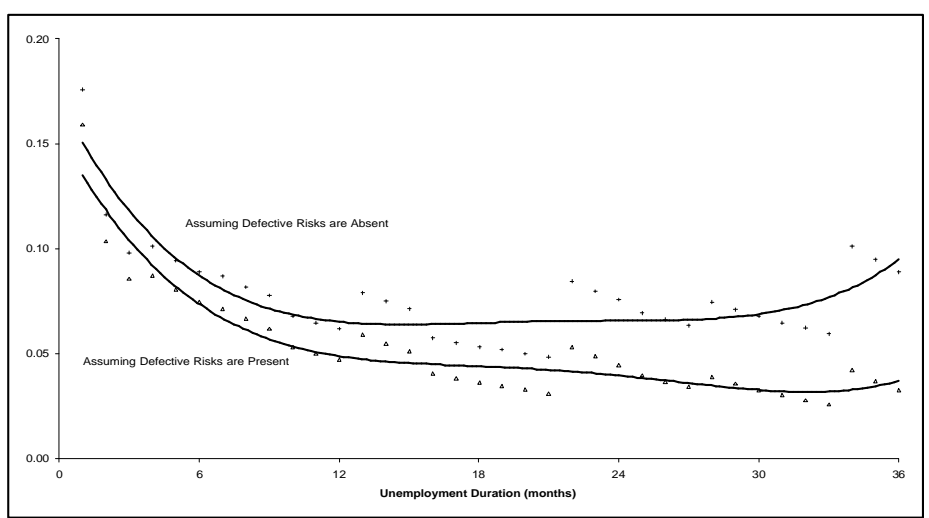

Note: Comparison of conditional (solely for U-E movers) and unconditional

(aggregating movers and stayers) hazard functions.

Values obtained from the specification in Table 2, column 5. 
Figure 8: Aggregate Survival Functions by UB status.

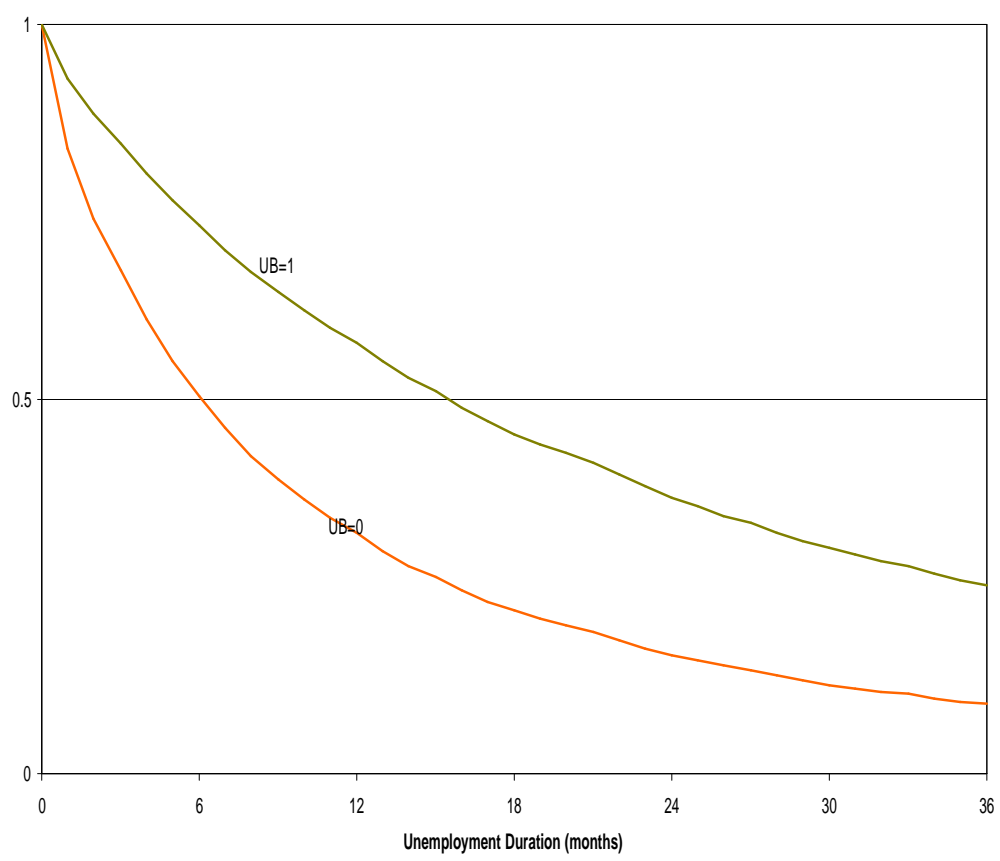

Note: Values obtained from the specification in Table 2, columns 5 and 6 .

The aggregate survival function converges to the proportion of (simultaneously)

employment and inactivity stayers.
Figure 9: Specific "Survival" Functions by UB Status.

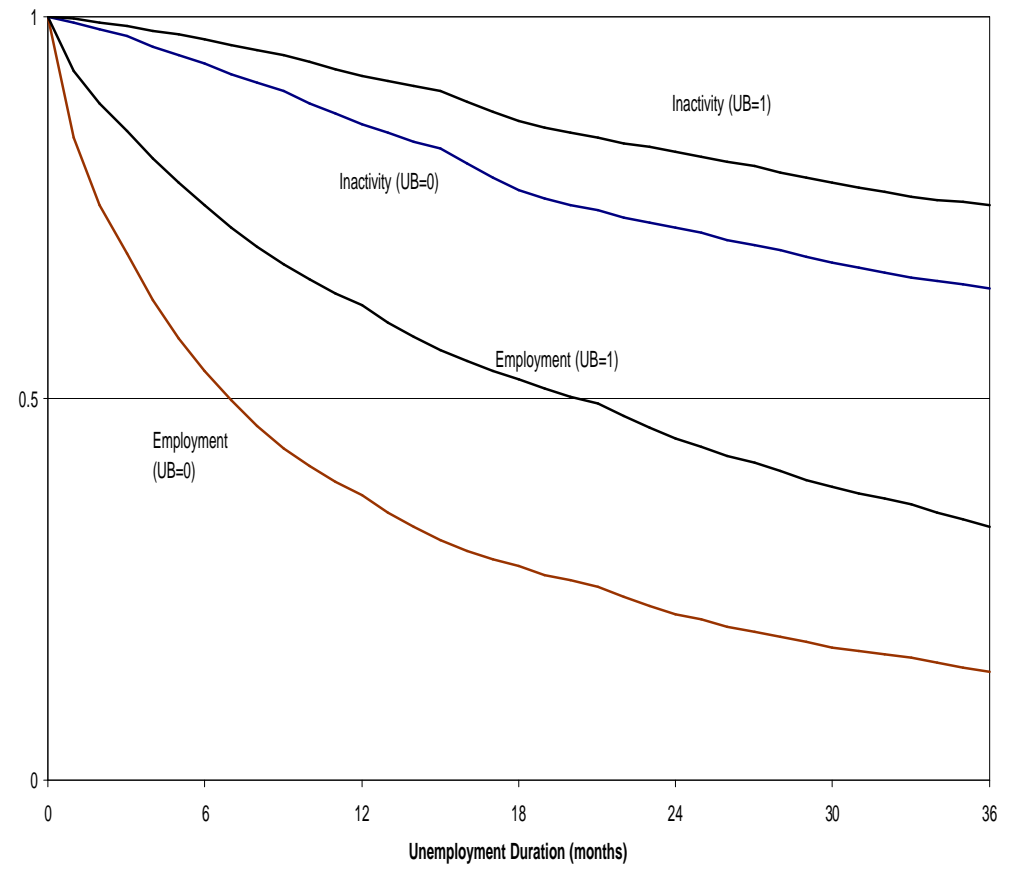

Note: Values obtained from the specification in Table 2, columns 5 and 6 .

The "specific" survival functions converge to the proportion of stayers in each destination. 
Figure 10: Defective Risk into Employment by Age and UB Status

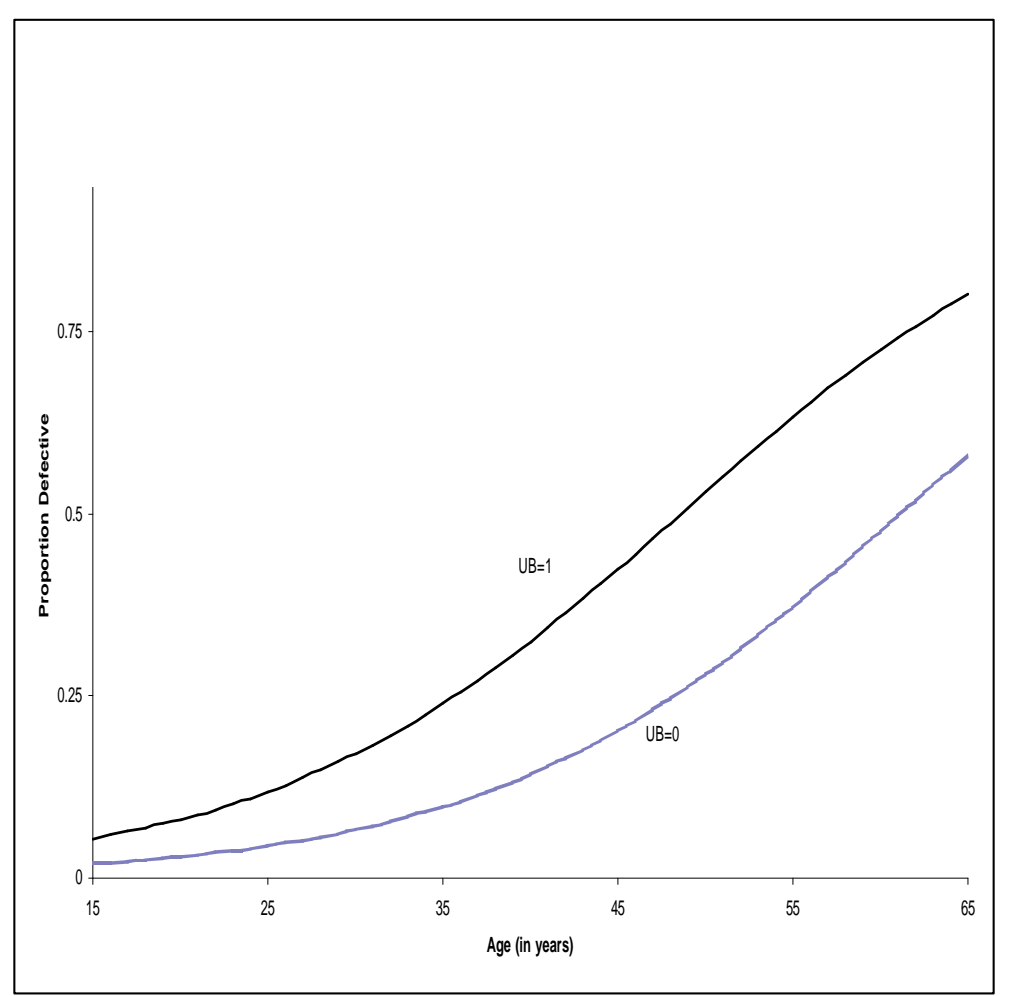

Note: Vertical axis gives the proportion of U-E stayers (non-employable) for individuals with mean characteristics for the continous variables and reference category for the binary variables.

Simulation values are obtained from the split-population equation estimates in Table 2, column 5.
Figure 11: Defective Risk into Inactivity by Age and UB Status

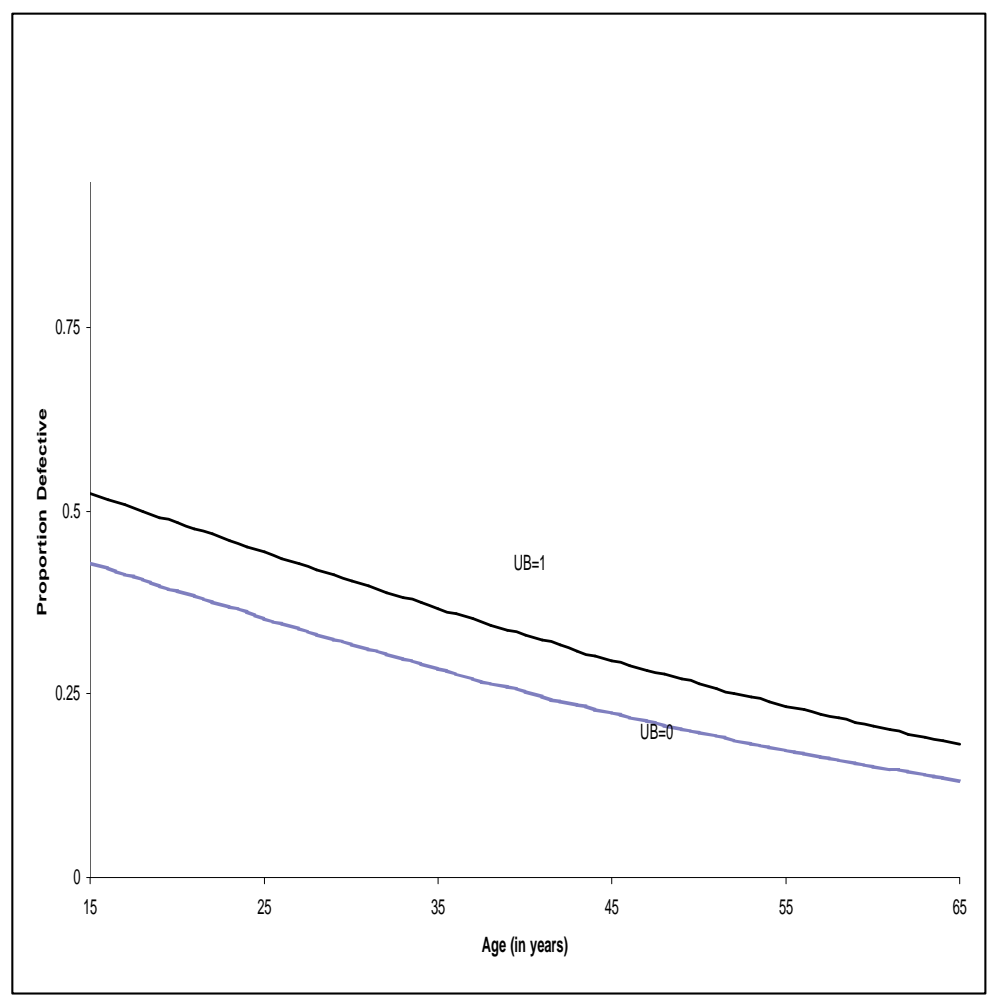

Note: Vertical axis gives the proportion of U-I stayers (not considering inactivity) for individuals

with mean characteristics for the continous variables and reference category for the binary

variables.

Simulation values are obtained from the split-population equation estimates in Table 2, column 6 . 
Table 1: Two-Destination Polynomial Hazard Regression Models $(n=9,451)$

\begin{tabular}{|c|c|c|c|c|c|c|}
\hline \multirow[b]{2}{*}{ Variable } & \multicolumn{2}{|c|}{ Transition to: } & \multicolumn{2}{|c|}{ Transition to: } & \multicolumn{2}{|c|}{ Transition to: } \\
\hline & Employment & Inactivity & Employment & Inactivity & Employment & Inactivity \\
\hline UB & $\begin{array}{l}-0.576 \\
(0.067)\end{array}$ & $\begin{array}{l}-0.570 \\
(0.156)\end{array}$ & $\begin{array}{l}-0.633 \\
(0.087)\end{array}$ & $\begin{array}{l}-0.703 \\
(0.242)\end{array}$ & $\begin{array}{l}-0.571 \\
(0.105)\end{array}$ & $\begin{array}{l}-0.580 \\
(0.244)\end{array}$ \\
\hline \multicolumn{7}{|l|}{ AGE GROUP } \\
\hline $25-29$ & $\begin{array}{c}0.025 \\
(0.080)\end{array}$ & $\begin{array}{c}-0.412 \\
(0.205)\end{array}$ & $\begin{array}{c}0.050 \\
(0.091)\end{array}$ & $\begin{array}{c}-0.535 \\
(0.295)\end{array}$ & $\begin{array}{c}0.072 \\
(0.098)\end{array}$ & $\begin{array}{l}-0.617 \\
(0.296)\end{array}$ \\
\hline $30-34$ & $\begin{array}{l}-0.104 \\
(0.097)\end{array}$ & $\begin{array}{l}-0.823 \\
(0.292)\end{array}$ & $\begin{array}{c}-0.104 \\
(0.110)\end{array}$ & $\begin{array}{l}-1.105 \\
(0.402)\end{array}$ & $\begin{array}{l}-0.045 \\
(0.122)\end{array}$ & $\begin{array}{l}-1.154 \\
(0.438)\end{array}$ \\
\hline $35-39$ & $\begin{array}{l}-0.247 \\
(0.119)\end{array}$ & $\begin{array}{l}-0.583 \\
(0.338)\end{array}$ & $\begin{array}{l}-0.258 \\
(0.137)\end{array}$ & $\begin{array}{l}-0.771 \\
(0.448)\end{array}$ & $\begin{array}{l}-0.138 \\
(0.154)\end{array}$ & $\begin{array}{l}-0.925 \\
(0.469)\end{array}$ \\
\hline $40-44$ & $\begin{array}{l}-0.098 \\
(0.118)\end{array}$ & $\begin{array}{c}0.037 \\
(0.296)\end{array}$ & $\begin{array}{l}-0.068 \\
(0.133)\end{array}$ & $\begin{array}{c}0.100 \\
(0.450)\end{array}$ & $\begin{array}{c}0.153 \\
(0.160)\end{array}$ & $\begin{array}{l}-0.147 \\
(0.438)\end{array}$ \\
\hline $45-49$ & $\begin{array}{l}-0.222 \\
(0.134)\end{array}$ & $\begin{array}{l}-0.076 \\
(0.326)\end{array}$ & $\begin{array}{l}-0.229 \\
(0.152)\end{array}$ & $\begin{array}{l}-0.139 \\
(0.478)\end{array}$ & $\begin{array}{l}-0.013 \\
(0.183)\end{array}$ & $\begin{array}{l}-0.327 \\
(0.469)\end{array}$ \\
\hline $50-54$ & $\begin{array}{l}-0.421 \\
(0.152)\end{array}$ & $\begin{array}{c}0.276 \\
(0.298)\end{array}$ & $\begin{array}{l}-0.451 \\
(0.173)\end{array}$ & $\begin{array}{c}0.307 \\
(0.466)\end{array}$ & $\begin{array}{l}-0.112 \\
(0.214)\end{array}$ & $\begin{array}{c}0.034 \\
(0.475)\end{array}$ \\
\hline $55+$ & $\begin{array}{l}-0.963 \\
(0.159)\end{array}$ & $\begin{array}{c}0.244 \\
(0.293)\end{array}$ & $\begin{array}{l}-1.038 \\
(0.188)\end{array}$ & $\begin{array}{c}0.151 \\
(0.455)\end{array}$ & $\begin{array}{l}-0.436 \\
(0.242)\end{array}$ & $\begin{array}{l}-0.098 \\
(0.451)\end{array}$ \\
\hline SCHOOLING & $\begin{array}{l}0.004 \\
0.008\end{array}$ & $\begin{array}{c}0.017 \\
(0.019)\end{array}$ & $\begin{array}{c}0.004 \\
(0.009)\end{array}$ & $\begin{array}{c}0.024 \\
(0.029)\end{array}$ & $\begin{array}{c}0.015 \\
(0.010)\end{array}$ & $\begin{array}{l}-0.051 \\
(0.032)\end{array}$ \\
\hline TENURE & $\begin{array}{l}-0.022 \\
(0.005)\end{array}$ & $\begin{array}{c}0.008 \\
(0.008)\end{array}$ & $\begin{array}{l}-0.025 \\
(0.006)\end{array}$ & $\begin{array}{c}0.015 \\
(0.013)\end{array}$ & $\begin{array}{l}-0.024 \\
(0.008)\end{array}$ & $\begin{array}{c}0.014 \\
(0.011)\end{array}$ \\
\hline MARRIED & $\begin{array}{c}0.307 \\
(0.078)\end{array}$ & $\begin{array}{l}-0.174 \\
(0.204)\end{array}$ & $\begin{array}{c}0.322 \\
(0.092)\end{array}$ & $\begin{array}{l}-0.445 \\
(0.312)\end{array}$ & $\begin{array}{c}0.197 \\
(0.107)\end{array}$ & $\begin{array}{l}-1.177 \\
(0.366)\end{array}$ \\
\hline FIRSTJOB & $\begin{array}{l}-0.410 \\
(0.093)\end{array}$ & $\begin{array}{c}0.368 \\
(0.169)\end{array}$ & $\begin{array}{l}-0.460 \\
(0.111)\end{array}$ & $\begin{array}{c}0.688 \\
(0.290)\end{array}$ & $\begin{array}{l}-0.541 \\
(0.123)\end{array}$ & $\begin{array}{c}0.627 \\
(0.271)\end{array}$ \\
\hline LAYOFF & $\begin{array}{c}0.008 \\
(0.090)\end{array}$ & $\begin{array}{l}-0.664 \\
(0.233)\end{array}$ & $\begin{array}{l}-0.013 \\
(0.102)\end{array}$ & $\begin{array}{l}-0.867 \\
(0.328)\end{array}$ & $\begin{array}{l}-0.071 \\
(0.114)\end{array}$ & $\begin{array}{l}-0.775 \\
(0.287)\end{array}$ \\
\hline END FIXED & $\begin{array}{c}0.171 \\
(0.062)\end{array}$ & $\begin{array}{l}-0.156 \\
(0.163)\end{array}$ & $\begin{array}{c}0.184 \\
(0.072)\end{array}$ & $\begin{array}{c}-0.291 \\
(0.231)\end{array}$ & $\begin{array}{c}0.176 \\
(0.079)\end{array}$ & $\begin{array}{l}-0.184 \\
(0.217)\end{array}$ \\
\hline UNEMPLOYMENT RATE & $\begin{array}{l}-0.022 \\
(0.028)\end{array}$ & $\begin{array}{c}-0.155 \\
(0.058)\end{array}$ & $\begin{array}{l}-0.028 \\
(0.031)\end{array}$ & $\begin{array}{l}-0.282 \\
(0.095)\end{array}$ & $\begin{array}{l}-0.017 \\
(0.034)\end{array}$ & $\begin{array}{l}-0.344 \\
(0.103)\end{array}$ \\
\hline CONSTANT & $\begin{array}{c}0.121 \\
(0.009)\end{array}$ & $\begin{array}{c}0.017 \\
(0.004)\end{array}$ & $\begin{array}{c}0.126 \\
(0.011)\end{array}$ & $\begin{array}{c}0.019 \\
(0.008)\end{array}$ & $\begin{array}{c}0.132 \\
(0.013)\end{array}$ & $\begin{array}{c}0.034 \\
(0.014)\end{array}$ \\
\hline $\mathrm{t} / 10$ & $\begin{array}{c}-0.080 \\
(0.012)\end{array}$ & $\begin{array}{c}0.007 \\
(0.008)\end{array}$ & $\begin{array}{c}-0.079 \\
(0.015)\end{array}$ & $\begin{array}{c}0.011 \\
(0.022)\end{array}$ & $\begin{array}{l}-0.083 \\
(0.019)\end{array}$ & $\begin{array}{c}0.022 \\
(0.037)\end{array}$ \\
\hline$t^{2} / 100$ & $\begin{array}{c}0.030 \\
(0.006)\end{array}$ & $\begin{array}{l}-0.004 \\
(0.004)\end{array}$ & $\begin{array}{c}0.033 \\
(0.008)\end{array}$ & $\begin{array}{c}0.011 \\
(0.024)\end{array}$ & $\begin{array}{c}0.039 \\
(0.012)\end{array}$ & $\begin{array}{c}0.010 \\
(0.033)\end{array}$ \\
\hline$t^{3} / 1,000$ & $\begin{array}{l}-0.005 \\
(0.001)\end{array}$ & $\begin{array}{c}0.001 \\
(0.001)\end{array}$ & $\begin{array}{l}-0.005 \\
(0.002)\end{array}$ & $\begin{array}{l}-0.005 \\
(0.007)\end{array}$ & $\begin{array}{l}-0.007 \\
(0.003)\end{array}$ & $\begin{array}{l}-0.005 \\
(0.010)\end{array}$ \\
\hline$t^{4} / 100,000$ & $\begin{array}{c}0.0025 \\
(0.0007)\end{array}$ & $\begin{array}{c}-0.0003 \\
(0.0051)\end{array}$ & $\begin{array}{c}0.0029 \\
(0.0010)\end{array}$ & $\begin{array}{c}0.0051 \\
(0.0073)\end{array}$ & $\begin{array}{c}0.0038 \\
(0.0017)\end{array}$ & $\begin{array}{c}0.0057 \\
(0.0089)\end{array}$ \\
\hline Sigma & & & $\begin{array}{c}0.389 \\
(0.154)\end{array}$ & $\begin{array}{c}1.569 \\
(0.339)\end{array}$ & $\begin{array}{c}0.465 \\
(0.164)\end{array}$ & $\begin{array}{c}0.974 \\
(0.385)\end{array}$ \\
\hline
\end{tabular}




\section{Split-Population Equation}

Mu

UB

AGE

\section{SCHOOLING}

TENURE

\section{MARRIED}

UNEMPLOYMENT RATE

$$
\begin{gathered}
4.301 \\
(0.972) \\
-1.424 \\
(0.504) \\
-0.187 \\
(0.047) \\
-0.132 \\
(0.057) \\
-0.022 \\
(0.024) \\
1.890 \\
(0.663) \\
-0.575 \\
(0.446)
\end{gathered}
$$

$-5041.73$

$-5019.93$
$-0.298$

(0.666)

0.029

$(0.030)$

0.226

$(0.081)$

$-0.028$

$(0.042)$

4.900

(7.073)

0.170

$(0.184)$

Log-likelihood

$-5048.12$

Asymptotic standard errors in parentheses 
Table 2: Two-Destination Piecewise-Constant Hazards Regression Models ( $n=9,451)$

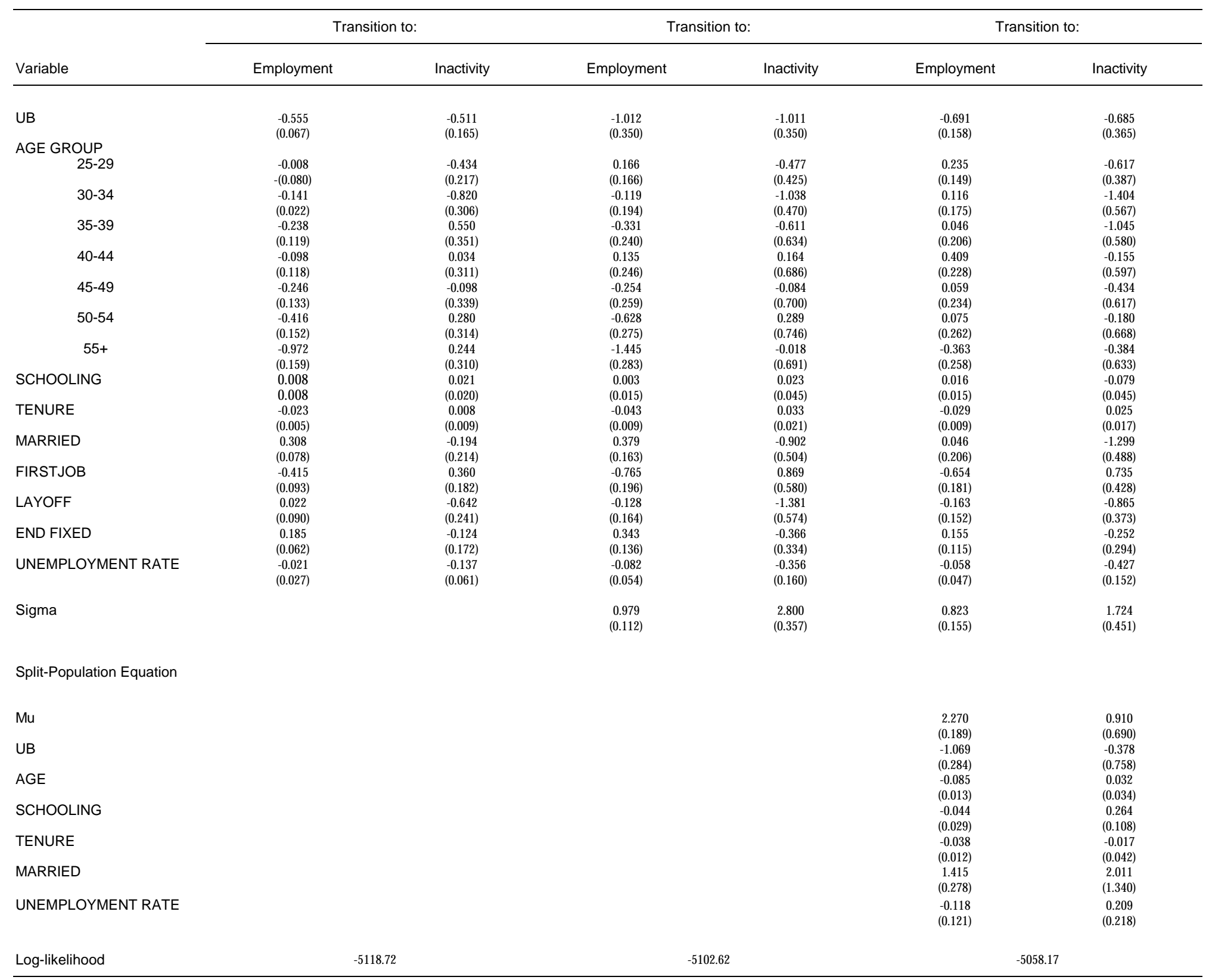

Asymptotic standard errors in parentheses 
Table 3: Simulations from the Split-Population Model

\begin{tabular}{|c|c|c|c|c|c|c|}
\hline & \multicolumn{2}{|c|}{$\underline{\text { Age }=20 \text { Years }}$} & \multicolumn{2}{|c|}{$\underline{\text { Age }=35 \text { Years }}$} & \multicolumn{2}{|c|}{$\underline{\text { Age }=50 \text { Years }}$} \\
\hline & $\mathrm{UI}=0$ & $U \mathrm{II}=1$ & $\mathrm{UI}=0$ & $U \mathrm{UI}=1$ & $\mathrm{UI}=0$ & $\mathrm{UI}=1$ \\
\hline \multicolumn{7}{|l|}{ Survival Rate after: } \\
\hline 3 months & 0.629 & 0.792 & 0.672 & 0.841 & 0.790 & 0.920 \\
\hline 12 months & 0.257 & 0.466 & 0.321 & 0.574 & 0.474 & 0.723 \\
\hline 36 months & 0.050 & 0.140 & 0.092 & 0.250 & 0.218 & 0.435 \\
\hline \multicolumn{7}{|l|}{ Defective Risk: } \\
\hline Employment & 0.029 & 0.081 & 0.094 & 0.231 & 0.371 & 0.632 \\
\hline Inactivity & 0.390 & 0.483 & 0.287 & 0.370 & 0.173 & 0.234 \\
\hline \multicolumn{7}{|l|}{$\begin{array}{l}\text { Median Duration: } \\
\quad \text { (in months) }\end{array}$} \\
\hline two destinations & 5 & 11 & 7 & 16 & 11 & 28 \\
\hline until employment & 7 & 14 & 7 & 21 & 24 & na \\
\hline
\end{tabular}

Note: The simulations are derived from Table 2, columns 5 and 6 
Appendix Table 1: Definition of Variables and Sample Means by Unemployment Benefit Recipiency and Destination

\begin{tabular}{|c|c|c|c|c|c|c|}
\hline \multirow[b]{2}{*}{ Variable } & \multicolumn{3}{|c|}{ Recipient } & \multicolumn{3}{|c|}{ Nonrecipient } \\
\hline & Unemployed & Employed & Inactive & Unemployed & Employed & Inactive \\
\hline $\begin{array}{l}\text { DURATION } \\
\text { elapsed unemployment in months }\end{array}$ & 12.082 & 9.027 & 15.250 & 16.138 & 9.919 & 13.548 \\
\hline $\begin{array}{l}\text { AGE } \\
\text { age in years }\end{array}$ & 42.456 & 36.048 & 43.875 & 31.184 & 29.457 & 30.158 \\
\hline $\begin{array}{l}\text { SCHOOLING } \\
\text { years of schooling completed }\end{array}$ & 5.765 & 5.912 & 5.312 & 7.089 & 7.104 & 7.743 \\
\hline $\begin{array}{l}\text { TENURE } \\
\text { years of tenure on previous job }\end{array}$ & 10.221 & 5.739 & 11.775 & 4.159 & 2.749 & 4.215 \\
\hline $\begin{array}{l}\text { JOBS } \\
\text { number of previous jobs }\end{array}$ & 3.431 & 3.958 & 3.250 & 2.419 & 3.011 & 1.892 \\
\hline $\begin{array}{l}\text { MARRIED } \\
=1 \text { if married, } 0 \text { otherwise }\end{array}$ & 0.754 & 0.636 & 0.734 & 0.338 & 0.369 & 0.278 \\
\hline $\begin{array}{l}\text { FIRSTJOB } \\
=1 \text { if looking for first job, } 0 \text { otherwise }\end{array}$ & & & & 0.234 & 0.174 & 0.361 \\
\hline $\begin{array}{l}\text { LAYOFF } \\
=1 \text { if job lost by reason of mass layoff, } 0 \text { otherwise }\end{array}$ & 0.316 & 0.227 & 0.203 & 0.093 & 0.082 & 0.046 \\
\hline $\begin{array}{l}\text { END FIXED } \\
=1 \text { if job lost through termination of a fixed-term contract, } 0 \text { otherwise }\end{array}$ & 0.243 & 0.382 & 0.266 & 0.244 & 0.332 & 0.174 \\
\hline $\begin{array}{l}\text { UNEMPLOYMENT RATE } \\
\text { quarterly unemployment rate }\end{array}$ & 6.648 & 6.570 & 6.684 & 6.557 & 6.498 & 6.388 \\
\hline $\mathrm{n}$ & 2770 & 330 & 64 & 4882 & 1164 & 241 \\
\hline
\end{tabular}


Appendix Table 2: Hazard Regression Model with Discrete Change After 6 Months of Unemployment ( $n=9,451)$

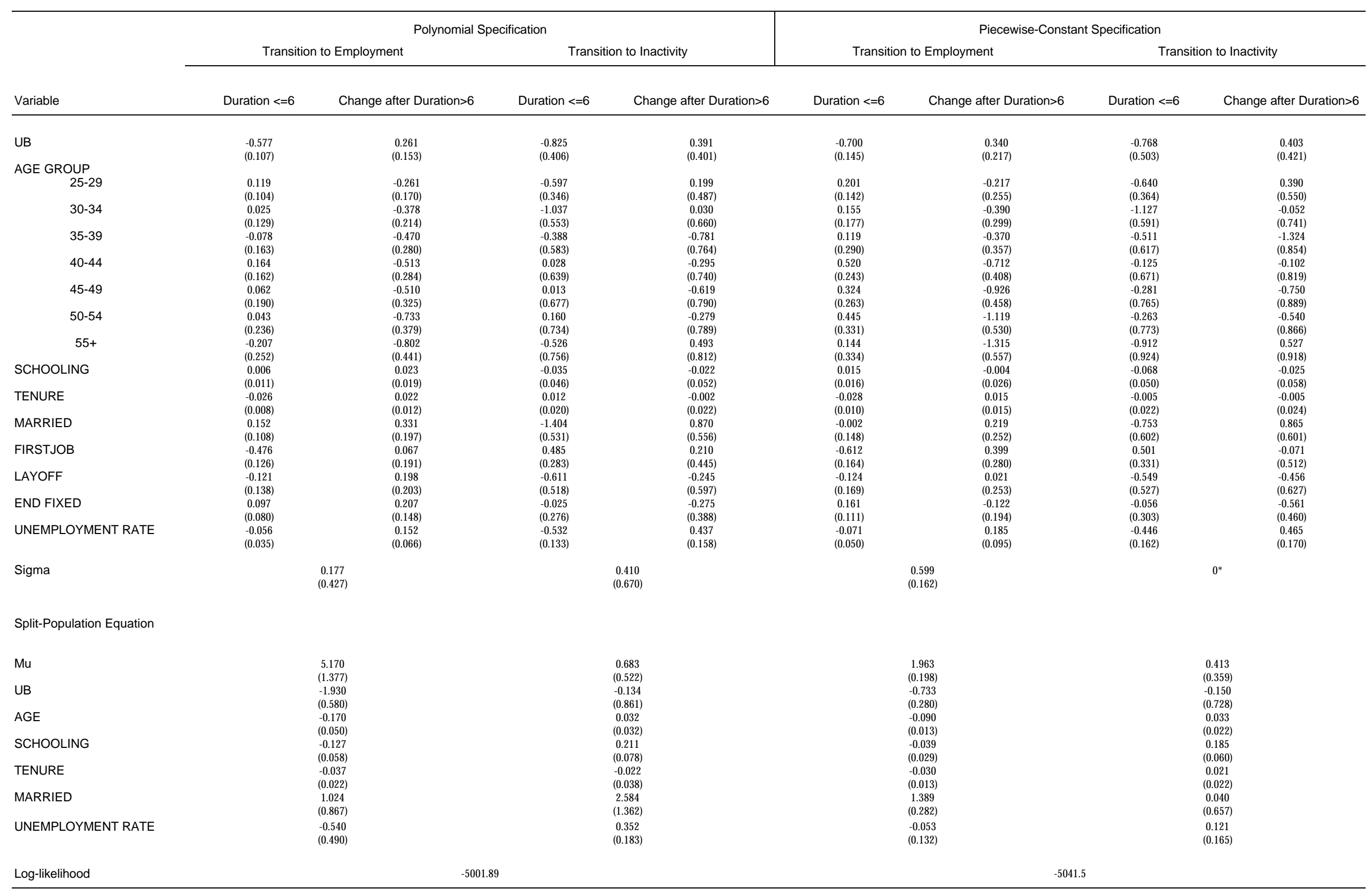

Asymptotic standard errors in parentheses

Gamma variance Parameter converged to 0 


\section{IZA Discussion Papers}
No. Author(s)
270
B. Augurzky
C. M. Schmidt
271
B. Augurzky
C. M. Schmidt
272
C. Belzil
J. Hansen

273

G. Saint-Paul

274

P.J. Pedersen

N. Smith

275

G. S. Epstein

T. Lecker

276

277

B. Amable

D. Gatti

R. Winter-Ebmer

278

T. M. Andersen

279

T. M. Andersen

280

P. Apps

R. Rees

281

G. Saint-Paul

282
J. Albrecht
A. Björklund
S. Vroman

Title

Area

Date

The Evaluation of Community-Based

6

03/01

Interventions: A Monte Carlo Study

The Propensity Score: A Means to An End

6

$03 / 01$

Heterogeneous Returns to Human Capital and

5

03/01

Dynamic Self-Selection

Distribution and Growth in an Economy with

5

03/01

Limited Needs

Unemployment Traps: Do Financial Dis-

3

03/01 incentives Matter?

Multi-Generation Model of Immigrant Earnings:

1

03/01

Theory and Application

The Impact of Product Market Competition on

5

03/01

Employment and Wages

Evaluating an Innovative Redundancy-Retraining

6

03/01

Project: The Austrian Steel Foundation

Welfare Policies, Labour Taxation and Inter-

2

$04 / 01$

national Integration

Product Market Integration, Wage Dispersion

2

04/01 and Unemployment

7

04/01

the Life Cycle

5

04/01

Elites

Is There a Glass Ceiling in Sweden?

5

04/01 

and the Rising Returns to Skill: US and France 1964-2000 
298

P. Telhado Pereira

Returns to Education and Wage Equations
A. Stutzer

R. Lalive

301

J. R. Frick

G. G. Wagner

302

G. S. Epstein

A. Weiss
H. Bonin
G. Abío
E. Berenguer
J. Gil
C. Patxot 
Costs
A. Frederiksen
E. K. Graversen Germany:

Overtime Work, Dual Job Holding and Taxation 

2000 

Industries: A Case Study of Upper Bavaria 